\title{
Cell-Instructive Alginate Hydrogels Targeting RhoA
}

\section{Journal Article}

\section{Author(s):}

Formica, Florian A.; Cavalli, Emma; Broguiere, Nicolas; Zenobi-Wong, Marcy (D)

Publication date:

2018-09-19

Permanent link:

https://doi.org/10.3929/ethz-b-000293885

\section{Rights / license:}

In Copyright - Non-Commercial Use Permitted

\section{Originally published in:}

Bioconjugate Chemistry 29(9), https://doi.org/10.1021/acs.bioconjchem.8b00436

\section{Funding acknowledgement:}

159783 - A Bio-inspired Cartilage Mimetic with Enhanced Chondrogenic and Anti-inflammatory Properties (SNF) 


\section{Cell-instructive alginate hydrogels targeting RhoA}

4

Florian A. Formica ${ }^{1}$, Emma Cavalli ${ }^{1}$, Nicolas Broguiere ${ }^{1}$, Marcy Zenobi-Wong ${ }^{1, \S}$
3 5 6

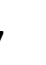

${ }^{1}$ Tissue Engineering \& Biofabrication, Department of Health Sciences and Technology, Swiss Federal Institute of Technology Zürich (ETH Zürich), Otto-Stern-Weg 7, 8093 Zürich, Switzerland

10

$\S$ Address for correspondence:

5 Prof. Marcy Zenobi-Wong (lead contact)

6 ETH Zürich

7 Tissue Engineering and Biofabrication

8 HPL J22

Otto-Stern-Weg 7

8093 Zürich, Switzerland

Email: marcy.zenobi@hest.ethz.ch

Phone: +41 446325089

3 


\section{Abstract}

Cellular processes involve dynamic rearrangement of the cytoskeleton. The GTPase RhoA plays a fundamental role in controlling cytoskeletal architecture. The phenotypic stability of chondrocytes is enhanced through inhibition of RhoA, whereas RhoA activation leads to dedifferentiation. We hypothesized that local inhibition of this pathway could induce chondrogenesis and cartilage regeneration. In this study, a novel alginate-derived hydrogel system was developed for sustained RhoA targeting. Specifically, an engineered variant of C. botulinum C3 transferase, a potent RhoA inhibitor, was immobilized onto a hydrogel to achieve sustained release and enzymatic activity. Chondrocytes encapsulated within this fully biocompatible, mechanically-stable scaffold produced a stable collagen type II-rich matrix in vitro which matured over a six-week period. Samples were implanted subcutaneously in mice, and similar production of a collagen type II-rich matrix was observed. The intrinsically versatile system has the potential to treat a number of clinical disorders, including osteoarthritis, caused by RhoA dysregulation.

\section{Introduction}

Spatial organization of the cytosol is key to a wide range of cellular processes such as cell migration, cytokinesis ${ }^{1}$ or cell differentiation. ${ }^{2,3}$ The cell is indeed able to perform these functions through rearrangement of its cytoskeleton. There is a strong correlation between cell shape and cytoskeleton architecture, whether it be during cellular locomotion, phases of the cell cycle or at a defined differentiation state. The cell responds to its physical and biochemical environment through cellsurface receptors triggering signals, ${ }^{4}$ which affect the Rho kinase family and regulate the cytoskeleton. This family of interrelated GTPases, the most widely studied being Cdc42, Rac1 and RhoA, control actin polymerization, the formation of stress fibers and microtubule organization. ${ }^{5-8}$

Mesenchymal stem cells (MSCs) are a typical example of cells whose differentiation can be influenced by controlling cell morphology and cytoskeletal architecture. Differentiation of MSCs has been shown to be dependent on cell density, cell shape and cytoskeletal tension. ${ }^{9}$ During osteogenesis, MSCs became more elongated and spread, while increasing the number of focal adhesions. ${ }^{10}$ Biologically, the cytoskeleton organization and cell contractility was shown to be largely regulated by RhoA in many cell types and cytoskeletal tension appeared to be mediated by ROCK, a direct RhoA effector. ${ }^{9}$ Inhibition of RhoA (e.g., by expressing dominant negative RhoA) or ROCK (e.g., by using the small molecule inhibitor Y-27632), enhanced adipogenesis while decreasing osteogenesis. ${ }^{9}$ Moreover, chondrogenesis was accompanied by cortical actin and a rounder cell morphology. ${ }^{11,12}$ Although strongly dependent on the three-dimensional environment, strong focal adhesion attachments were not essential for chondrogenesis. ${ }^{13}$ Chondrogenesis, leading to a lower amount of actin fibers and smaller cell size, was favored by a decrease in RhoA activity. In other words, chemical inhibition of the RhoA/ROCK pathways can control the chondrogenic differentiation of MSCs. ${ }^{14,15}$

Dedifferentiation can be defined as a biological mechanism where specialized cells degenerate to a more rudimentary state, in which they are incapable of fulfilling their biological function. ${ }^{16}$ For chondrocytes, dedifferentiation refers rather to a loss of key phenotypic markers of the cartilaginous extracellular matrix, specifically collagen type II and aggrecan, while redifferentiation refers to the restoration of their expression. When chondrocytes were cultured in a three-dimensional environment, chondrogenic genes such as SOX9 and collagen type II were upregulated, whereas when culturing the cells on a two-dimensional substrate, dedifferentiation was observed (Figure 1a). The physical environment of the cells is thought to play an essential role in this process via mechanosensing through cell membrane proteins. ${ }^{12}$ Numerous studies have been performed to try identifying the biochemical factors leading to chondrocyte de- and re-differentiation. Parreno et al. showed that 
cartilage matrix biosynthesis was tightly regulated by actin polymerization. ${ }^{17}$ Chemical induction of actin depolymerization in dedifferentiated chondrocytes induced upregulation of SOX9 while repressing collagen type I. ${ }^{17}$ The authors suggested that the actin polymerization promoted the expression of a collagen type I-rich fibroblastic matrix through myocardin-related transcription factors (MRTF), which, in turns, led to the formation of fibrocartilage. ${ }^{17}$ MRTF signaling to the nucleus is controlled by the state of actin (filamentous F-actin or free globular G-actin).$^{18}$

RhoA is a particularly important mediator of cytoskeleton in chondrogenesis., ${ }^{5,19}$ Studies have shown the effect of RhoA on chondrocyte dedifferentiation and highlighted the role of two important downstream effectors, ROCK and mDia. ${ }^{5}$ Inhibiting members of this signaling pathway induced a chondrogenic phenotype. In particular, treating passaged, dedifferentiated chondrocytes cultured on tissue culture plastic with a RhoA inhibitor, C3 transferase, stimulated the re-expression of collagen type II, a marker of healthy cartilage (Figure $1 \mathrm{~b}$ ). ${ }^{20}$ On the biological level, the inhibition of ROCK induced SOX9 upregulation, glycosaminoglycan synthesis, and cells adopted a spherical morphology. ${ }^{14}$ A consensus phosphorylation site was identified on Ser ${ }^{181}$ of SOX9. Surprisingly, its phosphorylation and subsequent nuclear translocation was increased by ROCK overexpression and RhoA activation in SW1353 chondrosarcoma cells. ${ }^{21}$ On the macroscopic level, RhoA/ROCK activation is thought to be partly responsible for cartilage degradation in joint conditions such as osteoarthritis. ${ }^{22}$ The activation of Rho/ROCK signaling by TGF- $\alpha$ (i.e., TGF- $\alpha$ expression levels are high in osteoarthritic cartilage ${ }^{22}$ ) and its inhibition by $\mathrm{C} 3$ transferase or $\mathrm{Y}-27632$ were extensively studied in primary chondrocytes and osteochondral explants. The results indicated that high RhoA/ROCK levels induce chondrocyte proliferation, catabolic activity and subsequent cartilage extracellular matrix (ECM) degradation. ${ }^{22}$

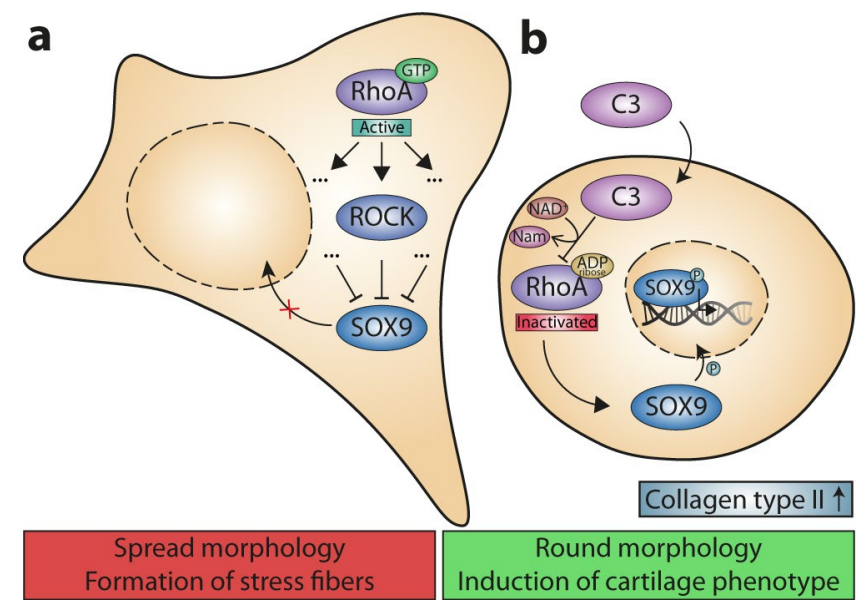

Figure 1. (one-column, $8.45 \mathrm{~cm}$ ) Chondrocyte dedifferentiation and RhoA inhibition. (a) Chondrocytes cultured on tissue culture plastic evolve to a fibroblastic morphology characterized by prominent stress fibers. Activation of RhoA or one of its effectors, ROCK, is believed to have an inhibitory effect on SOX9 expression, leading to loss of collagen type II and dedifferentiation. (b) Culture of chondrocytes in $3 D$ and/or with the Rho inhibitor C3 transferase (C3) prevents dedifferentiation. Here, RhoA is inhibited through the ADP-ribosylation of its active site. The reaction involves the conversion of nicotinamide adenine dinucleotide $\left(N A D^{+}\right)$into nicotinamide (Nam). Subsequently, SOX9 transcriptional activity leads to an increase in collagen type II.

In cartilage engineering, three-dimensional cell culture has become the gold standard to support chondrocyte culture. In particular, polysaccharide hydrogels such as alginate showed excellent biocompatibility and chondrogenic properties. ${ }^{23-26}$ Although these hydrogels promote a cortical cytoskeletal arrangement and a round cell shape, they are often insufficient to promote full redifferentiation. Controlling the cytoskeleton by the use of advanced cell-instructive materials has gained popularity in the last decade, and cell behavior could be influenced by tuning the topographic features of the cell environment. ${ }^{27}$ The combination of a biochemical stimulus with a tailored threedimensional environment represents a novel way of efficiently influencing cell behavior. Moreover, 
cross-linking of therapeutic molecules to a three-dimensional matrix is a safe method to provide a local, sustained and controlled delivery, as opposed to systemic delivery. ${ }^{28}$

In the present work, a new cell-instructive material targeting Rho GTPase activity of resident cells was developed with the aim of achieving enhanced chondrogenesis. To achieve this, an alginate-based hydrogel was conjugated to a RhoA inhibitor under physiological conditions. Briefly, the polysaccharide backbone, functionalized with vinyl sulfone moieties, reacted with a cysteine residue by Michael addition (Figure 2). The RhoA signaling pathway is potently inhibited by the enzyme C3 transferase, isolated from Clostridium botulinum. ${ }^{29} \mathrm{~A} \mathrm{C} 3$ variant including a cysteine residue at its $\mathrm{C}$-terminus was designed, allowing its cross-linking to the functionalized alginate (Figure $2 \mathrm{~b}$ ). The fusion protein, $\mathrm{C} 3 \mathrm{C}$, chemically inactivates RhoA, RhoB and RhoC by ADP-ribosylating their active site. As chondrocytes express matrix metalloproteinases (MMPs), especially in osteoarthritic environments, ${ }^{30}$ an MMPcleavable linker was introduced between the C3 gene and the cysteine cassette as a release mechanism. Also, cell permeation was enhanced by the addition of a cell-penetrating peptide from the HIV-1 Tat protein. The sustained enzymatic activity and stability of the $\mathrm{C} 3 \mathrm{C}$ variant is shown, and the strong chondrogenic potential of the $\mathrm{C} 3 \mathrm{C}$-loaded hydrogel was demonstrated in vitro and in vivo.
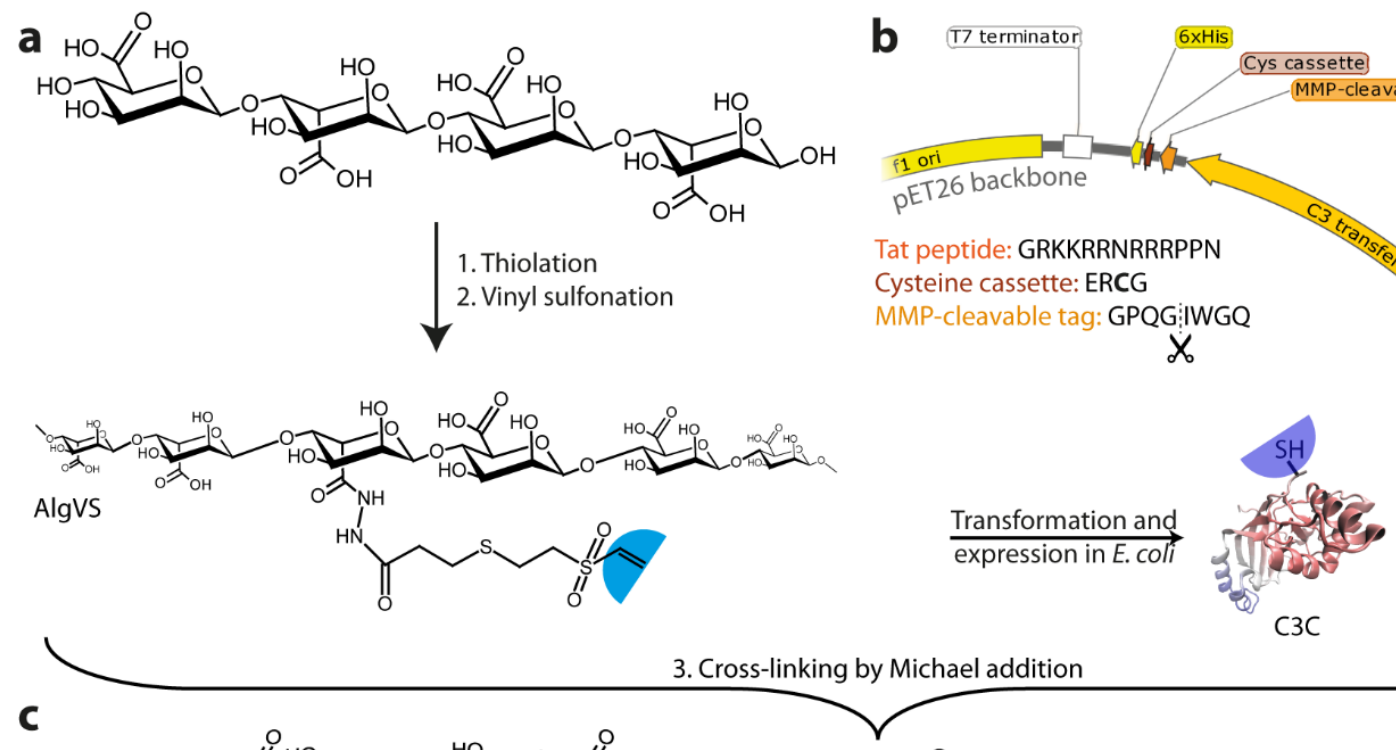

C
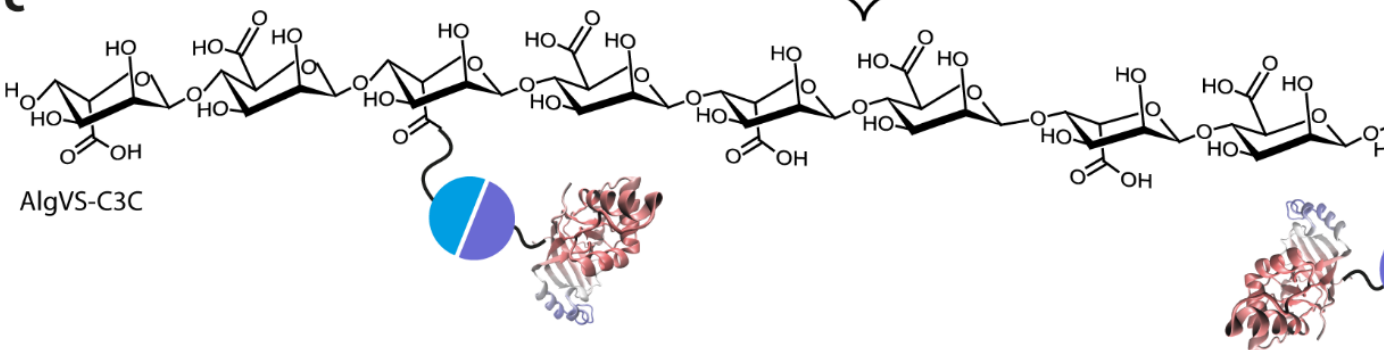

Figure 2. (two-column, $17.5 \mathrm{~cm}$ ) Preparation of the $C 3$ transferase-functionalized hydrogels. (a) Alginate was modified in two steps - thiolation and vinyl sulfonation - leading to AlgVS, containing a Michael addition acceptor (light blue). (b) A fusion C3 transferase variant was designed and subcloned into the $P E T-26$ expression vector for transformation in E. coli. Specifically, the C3C variant introduced i) a HIV-1 Tat peptide for cell penetration, ii) a cysteine cassette as Michael addition donor (dark blue) and iii) an MMP-cleavable sequence allowing the release from the hydrogel by enzymatic cleavage. (c) The two components were reacted together under physiological conditions, leading to a stable C3C-conjugated hydrogel precursor, which was then be gelled by ionic (calcium) cross-linking.

\section{Results}

After the two reaction steps - thiolation and vinyl sulfonation - the product, alginate vinyl sulfone (AlgVS), was characterized and its substitution degree estimated by proton NMR (Figure 3a). Vinyl 
sulfone protons have a characteristic signal at $6.8,6.4$ and $6.3 \mathrm{ppm}$ while the alginate backbone protons have a chemical shift at 3.3-4.2 ppm. For each successfully substituted mannuronate or guluronate monomer, the three vinyl sulfone protons correspond to five backbone protons. Therefore, the degree of substitution (DS) was calculated using the equation below:

$$
D S=\frac{5}{3} \frac{\sum I_{v S}}{\sum I_{\text {alg }}}
$$

where $I_{v s}$ is the intensity of each vinyl sulfone proton and $I_{a l g}$ the intensity of alginate protons and was found to reach $9 \%$ for the batch analyzed.

To confirm that the reactions did not reduce the molecular weight of alginate, polymers were analyzed using gel permeation chromatography (Figure $3 b$ ). No significant shift in the retention time was observed, indicating negligible degradation.

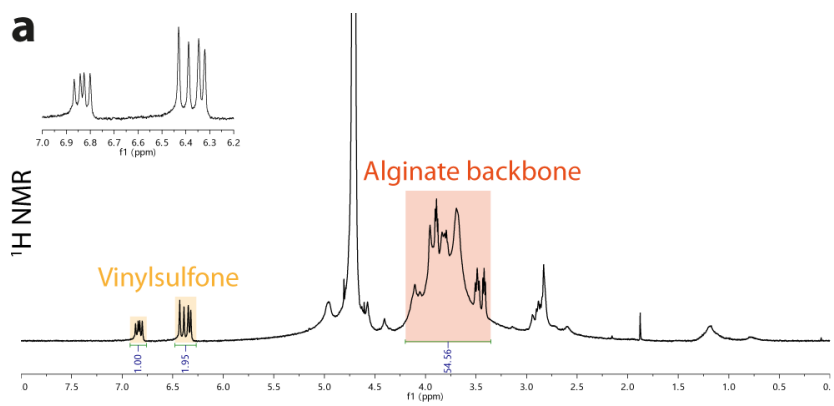

\section{b Gel permeation chromatography}

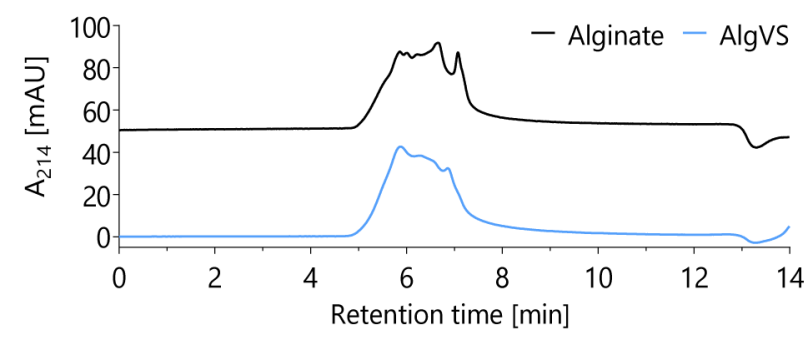

Figure 3. (one-column, $8.45 \mathrm{~cm}$ ) Characterization of alginate vinyl sulfone. (a) ${ }^{1} \mathrm{H} N M R\left(400 \mathrm{MHz}, \mathrm{D}_{2} \mathrm{O}\right)$ was performed on functionalized alginate, AlgVS, after the two-step procedure and dialysis. The substitution degree was calculated by normalizing the vinyl sulfone peaks (light orange) with the polymer backbone peaks (dark orange) and was found to reach 9\%. (b) The modification of alginate leading to AlgVS showed no degradation regarding molecular weight, as assessed by gel permeation chromatography.

\section{Protein conjugation to alginate hydrogels}

The hydrogel precursor was incubated with a fluorescent model protein (BSA-TexasRed, $2 \mu \mathrm{M}$ ) to spectroscopically quantify the binding and retention of cysteine-containing proteins to AlgVS. BSA contains thirty-five cysteine residues, leaving one free cysteine for the conjugation reaction. Hydrogels were then cross-linked with $\mathrm{Ca}^{2+}$ and transferred to saline to wash out unbound protein (Figure 4). The amount of protein physically retained in unmodified alginate was very low $(9.2 \pm 3.7 \%)$ whereas 55.0 $\pm 18.7 \%$ of BSA-TexasRed was bound to AlgVS by Michael addition $(* p<0.05)$. It should be noted that the manufacturer does not specify the details on the preparation of the TexasRed conjugate. Therefore, destruction of thiols during TexasRed substitution or cysteine oxidation to cystine could have reduced the number of available thiols for Michael addition. 

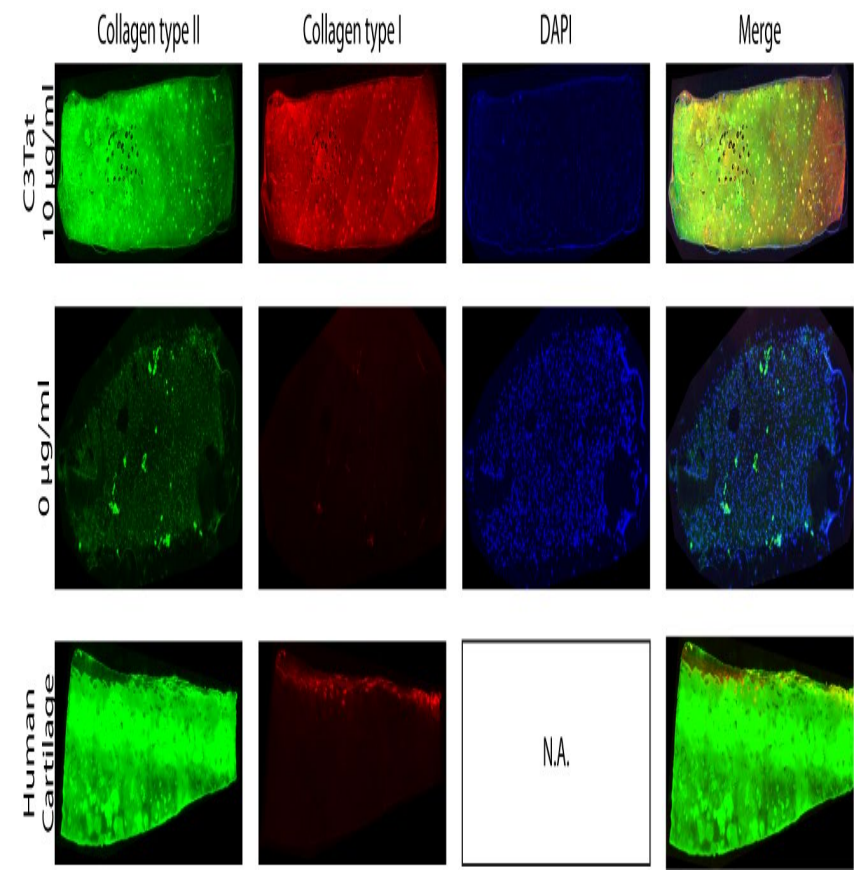

Figure 4. (one-column, $8.45 \mathrm{~cm}$ ) Protein binding to alginate vinyl sulfone. To assess the binding of proteins to AlgVS, fluorescent BSA-TexasRed was used. After incubating the protein solution with the hydrogel precursor, the gels were ionically cross-linked and imaged. After seven days of incubation in a large volume of $0.9 \% \mathrm{NaCl}$, the amount of BSA retained in the hydrogel was quantified by fluorescence microscopy. The amount of protein retained in AlgVS was 6-fold that of the control and $55.0 \pm 18.7 \%$ of the initially adsorbed protein; ${ }^{*} p<0.05, n=3$.

Sustained C3C glycohydrolase activity

An HPLC-based activity assay showed that the engineered C3 variant had a high and sustained enzymatic activity. In the absence of a protein substrate, the $\mathrm{C} 3$ exoenzyme can convert oxidized nicotinamide adenine dinucleotide $\left(\mathrm{NAD}^{+}\right)$into adenosine diphosphate-ribose (ADP-ribose) and nicotinamide by cleaving the carbon-nitrogen bond. ${ }^{31}$ This glycohydrolase activity was quantified by incubating the $\mathrm{C} 3 \mathrm{C}$ enzyme $(500 \mathrm{nM})$ with $\mathrm{NAD}^{+}(400 \mu \mathrm{M})$ and monitoring the product formation and substrate consumption over time (Figure $5 a-b$ ). By linear regression fitting, the enzymatic activity was calculated to be $18.9 \pm 0.9 \mathrm{U} / \mathrm{mg}$. This value was in the range of the reported values in the literature $(30.2 \pm 2.0 \mathrm{U} / \mathrm{mg}) .{ }^{31} \mathrm{~A}$ degradation product was identified as ADP-ribose was being produced. This primary product slowly degraded into adenosine monophosphate (AMP) by cleavage of the phosphodiester bond, and could be identified by HPLC. 
a

Gel permeation chromatography

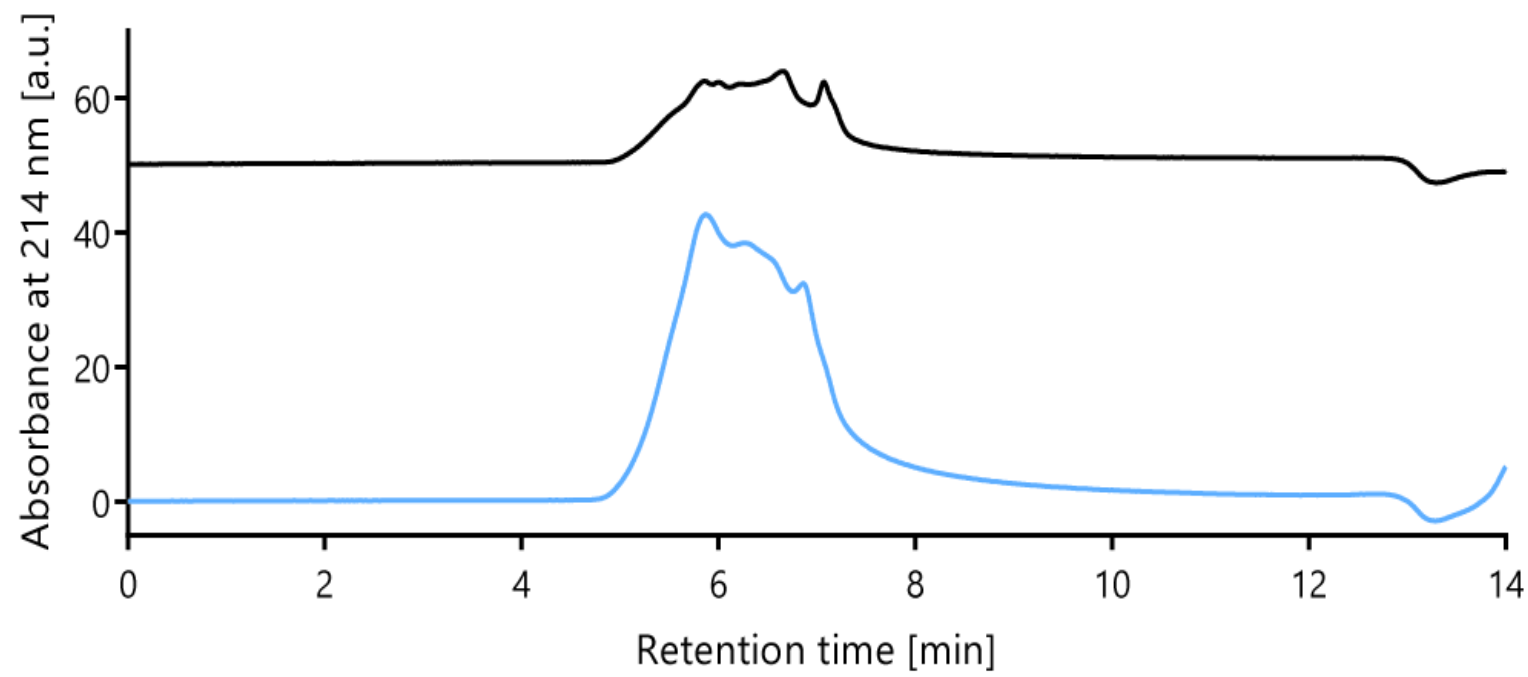

b

\section{Unconfined compression}
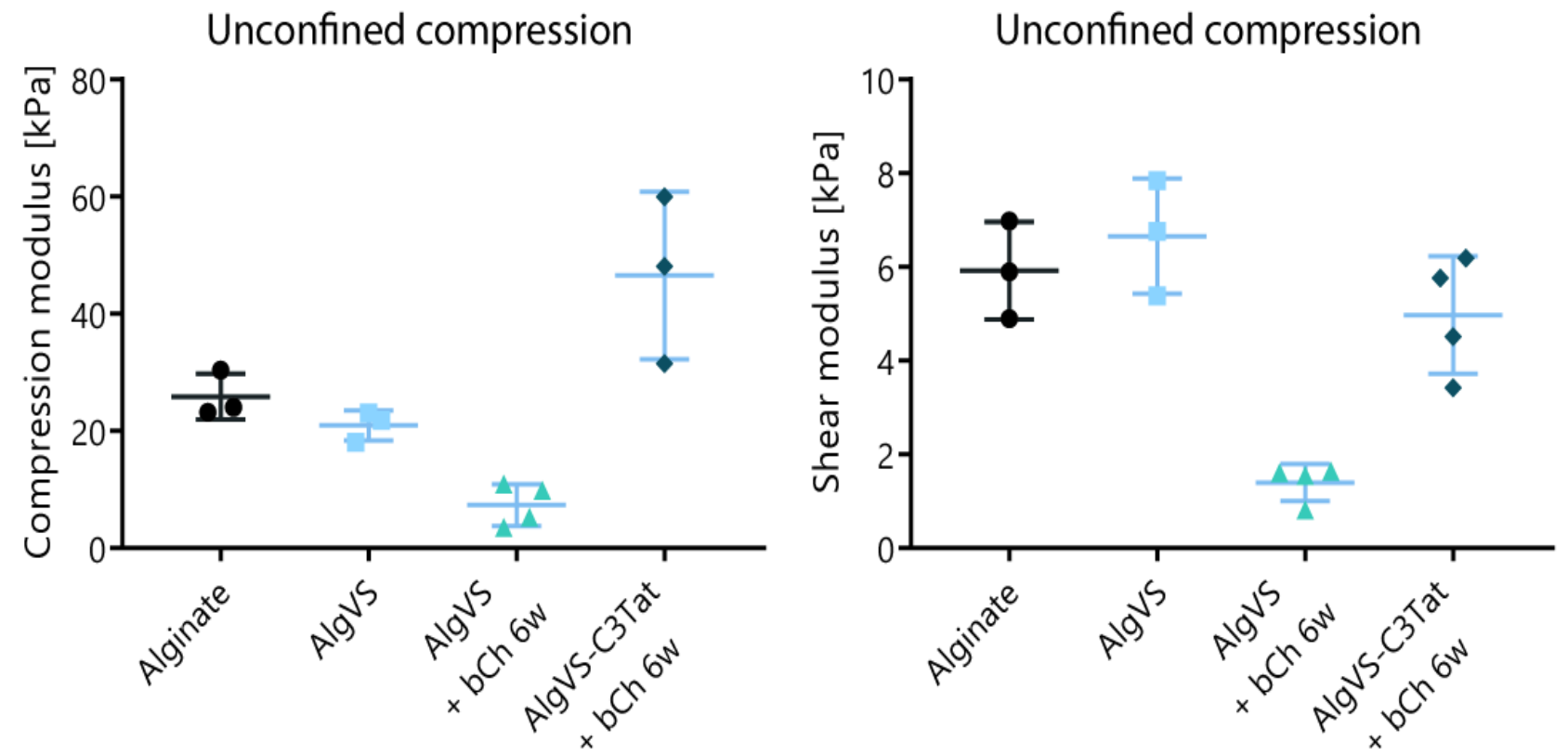

Figure 5. (two-column, $17.5 \mathrm{~cm}$ ) Enzymatic of the C3C variant. (a) The in vitro glycohydrolase activity of the C3C variant was assessed by HPLC over 100 hours. NAD+ was used as a substrate while ADP-ribose (ADPR) was produced. At later time points, ADPR further degraded into AMP. (b) The peak areas in (a) were quantified, resulting in an enzymatic activity constant of 18.9 $\pm 0.9 \mathrm{U} / \mathrm{mg}\left(R^{2}=0.973\right)$. (c) The C3C stability over time was assessed by keeping the enzyme at $37^{\circ} \mathrm{C}$ for four weeks, before substrate addition.

As chondrogenesis and cartilage repair occur over long periods of time, we assessed the long-term stability and activity of $\mathrm{C} 3 \mathrm{C}$ and compared it to freshly thawed enzyme (Figure $5 \mathrm{c}$ ). At equal reaction times, the fresh enzyme converted more than $80 \%$ of the substrate into ADP-ribose or AMP while the enzyme that was pre-incubated at $37{ }^{\circ} \mathrm{C}$ for four weeks converted about $71 \%$ of the substrate. As a negative control, the $\mathrm{NAD}^{+}$substrate was incubated without enzyme to account for spontaneous degradation (12\%).

Effect of C3 transferase and AlgVS on cell viability and chondrogenic markers investigated with bovine and human chondrocytes. The viability of bovine chondrocytes was not 
significantly affected by one-week incubation with C3C (96.3 $\pm 0.6 \%$ (control) vs $94.4 \pm 1.5 \%$ (highest concentration), Figure 6a). Human chondrocytes were slightly more sensitive to high doses of C3C ( 97.7 $\pm 1.3 \%$ (control) vs $91.4 \pm 1.3 \%$ (highest dosage), $* * * * p<0.0001$, Figure $6 a$ ). The effect of vinyl sulfonation on cell viability was assessed after one week and no significant difference was observed on both bovine ( $94.0 \pm 1.3 \%$ (Alg) vs $96.2 \pm 0.6 \%$ (AlgVS)) and human chondrocytes $(88.0 \pm 3.2 \%$ (Alg) vs $91.3 \pm 4.2 \%$ (AlgVS)).

a

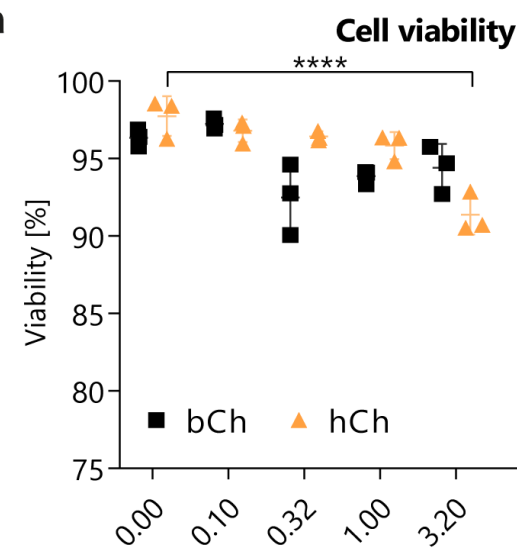

C b

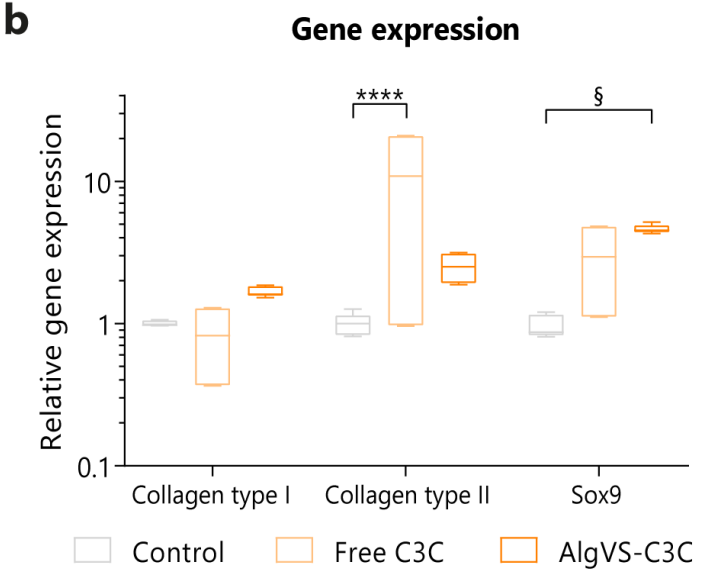

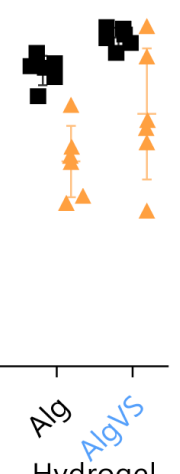

Hydrogel
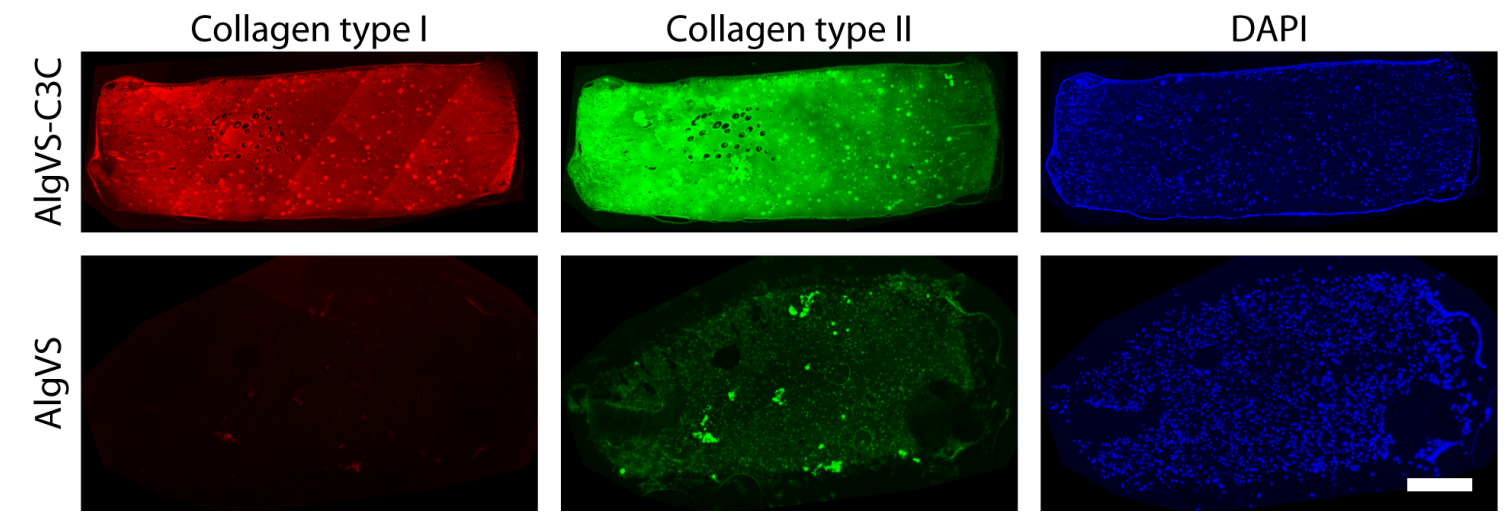

Figure 6. (two-column, $17.5 \mathrm{~cm}$ ) Biological effects of C3C. (a) The viability of human and bovine chondrocytes was quantified by live/dead assay after one-week exposure to various amounts of C3C (left) and after encpsulation in AlgVS hydrogels (right). The viability of bovine chondrocytes was unaffected by $\mathrm{C} 3 \mathrm{C}$, whereas the highest concentration of $\mathrm{C} 3 \mathrm{C}$ slightly decreased the viability of human chondrocytes; ${ }^{* * * *} p<0.0001, n=3$. AlgVS did not significantly alter the viability of chondrocytes compared to alginate controls. (b) The gene expression of collagen types I \& II and SOX9 were quantified at three weeks by qRT-PCR. Bovine chondrocytes were encapsulated into AlgVS-C3C hydrogels (dark orange) or in unmodified alginate, with C3C supplementation $(0.4 \mu \mathrm{g} / \mathrm{mL}$, light orange) or without (grey). A trend was observed indicating the upregulation of chondrogenic genes with C3C treatment; $\S p=0.13, * * * * p<0.0001, n=3$. (c) Immunohistochemistry was performed on AlgVS hydrogels with/without $\mathrm{C} 3 \mathrm{C}$ conjugation, for collagen types I and II. Both proteins were strongly upregulated in the presence of C3C. Scale bar: $500 \mu \mathrm{m}$.

The expression of chondrogenic genes was quantified after three weeks exposure to C3C (Figure 6b). The final construct AlgVS-C3C (dark orange) and the free form of C3C (light orange) were compared to an untreated alginate control (grey). The expression of collagen type I, marker of fibrocartilage, was not significantly affected by the presence of $\mathrm{C} 3 \mathrm{C}$ while free $\mathrm{C} 3 \mathrm{C}$ led to a significant upregulation of Collagen type II. The trend observed on the mRNA level was supported by immunohistochemistry, where a strong effect was identified with $\mathrm{C} 3 \mathrm{C}$ treatment (Figure $6 \mathrm{c}$ ). However, on the protein level, both collagen types were strongly upregulated upon $\mathrm{C} 3 \mathrm{C}$ treatment.

Mechanical properties

The compressive modulus $E$ and Ogden shear modulus $\mu$ of the alginate samples were measured in unconfined compression (Figure 7). The hyperelastic Ogden model accurately describes the behavior 
of certain hydrogels and soft tissues where the Young's modulus increases with compressive strain. ${ }^{32}$ Several Ogden material model constants can be extracted from the curve fitting. ${ }^{33}$ The chondrocyteseeded scaffolds were quantified after a six-week maturation period in vitro (Figure 7, right) and compared to initial values (Figure 7, left). It was assumed that, at day 0 , the cells had a negligible impact on the mechanical properties of the hydrogels. At day 0 , there were no significant differences in moduli between alginate and AlgVS hydrogels. The compression modulus $E$ was $25.9 \pm 3.9 \mathrm{kPa}$ (Alginate) and $20.9 \pm 2.6 \mathrm{kPa}$ (AlgVS), while the shear modulus $\mu$ was $5.9 \pm 1.0 \mathrm{kPa}$ (Alginate) and $6.7 \pm 1.2 \mathrm{kPa}$ (AlgVS). After six weeks in culture, chondrocytes (bCh)-seeded scaffolds exhibited significant differences between the C3C-loaded hydrogel (AlgVS-C3C) and the unloaded control (AlgVS). Whereas the control samples lost strength after six weeks incubation at $37^{\circ} \mathrm{C}\left(7.4 \pm 3.6\right.$ and $1.4 \pm 0.4 \mathrm{kPa}\left({ }^{*} \mathrm{p}<0.05,{ }^{* * *}\right.$ $\mathrm{p}<0.001$ ) for the compressive and shear moduli, respectively), the C3C-loaded gels matured to improve the mechanical strength $\left(46.5 \pm 14.3\right.$ and $5.0 \pm 1.3 \mathrm{kPa}\left({ }^{* *} p<0.01, * * * p<0.001\right)$ for the compressive and shear moduli, respectively).

\section{Mechanical properties}

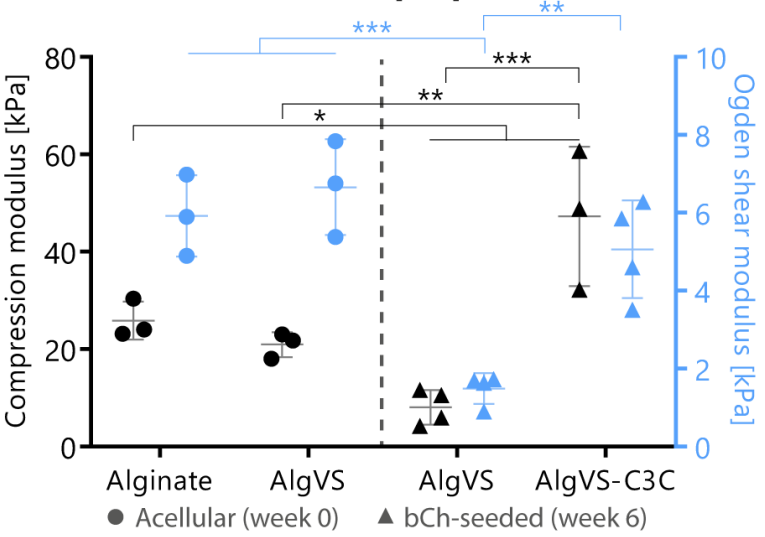

Figure 7. (one-column, $8.45 \mathrm{~cm}$ ) Mechanical properties of C3C-loaded AlgVS hydrogels. The mechanical properties of alginate and AlgVS were measured in an unconfined compression setup on acellular scaffolds, at day 0 (left $\mathbf{0}$ ) and bCh-seeded scaffolds, after six weeks of culture (right $\mathbf{\Delta}$ ). The compression modulus (black) was calculated between $5 \%$ and $15 \%$ strain, and the Ogden shear modulus (blue) was calculated by curve-fitting until $90 \%$ strain of an Ogden hyperelastic model (first order). Samples with immobilized C3C performed significantly better compared to AlgVS alone; ${ }^{*} p<0.05,{ }^{* *} p<0.01,{ }^{* * *} p$ $<0.001 ; n=3$.

In vitro and in vivo cartilage extracellular matrix biosynthesis

To investigate the production of a collagen type II-rich matrix as well as its retention in vivo, two sets of AlgVS-C3C hydrogels were implanted subcutaneously in the back of nude mice and kept for three weeks. In the first dataset, hydrogels were precultured for three weeks, while, in the second dataset, the gels were prepared shortly before implantation. Collagen types I and II were evaluated by immunohistochemistry and compared to cells encapsulated in unmodified alginate. In the in vitro samples, the AlgVS-C3C samples led to a stronger matrix production than the alginate controls (Figure 8 , left). Moreover, a maturation of the scaffolds was observed over time, as shown by the significantly more intense staining at week 6 , compared to week 3 . Another characteristic of all samples was the correlation between collagen types I and II. As the production of collagen type II was increased, collagen type I was also upregulated.

AlgVS-C3C also led to an increased matrix production in vivo (Figure 8 , right). However, at equal implantation times, the samples that were freshly prepared had an increased matrix production, compared to the samples precultured for three weeks. The hydrogels that led to the best performance, that is a high production of collagen type II and moderate production of collagen type I, were freshly prepared AlgVS-C3C (Figure 8, In vivo, AlgVS-C3C, -). The results indicated that the collagen II-rich matrix produced during the preculture time was partially lost when implanted (Figure 8 , In vivo, AlgVS- 
C3C, Precult.). Alginate control hydrogels induced a higher production of collagen type I when precultured in vitro for three weeks compared to freshly-prepared (-) gels. Bovine cartilage and a rabbit IgG isotope control are shown as positive and negative control, respectively (Figure 8, bottom).
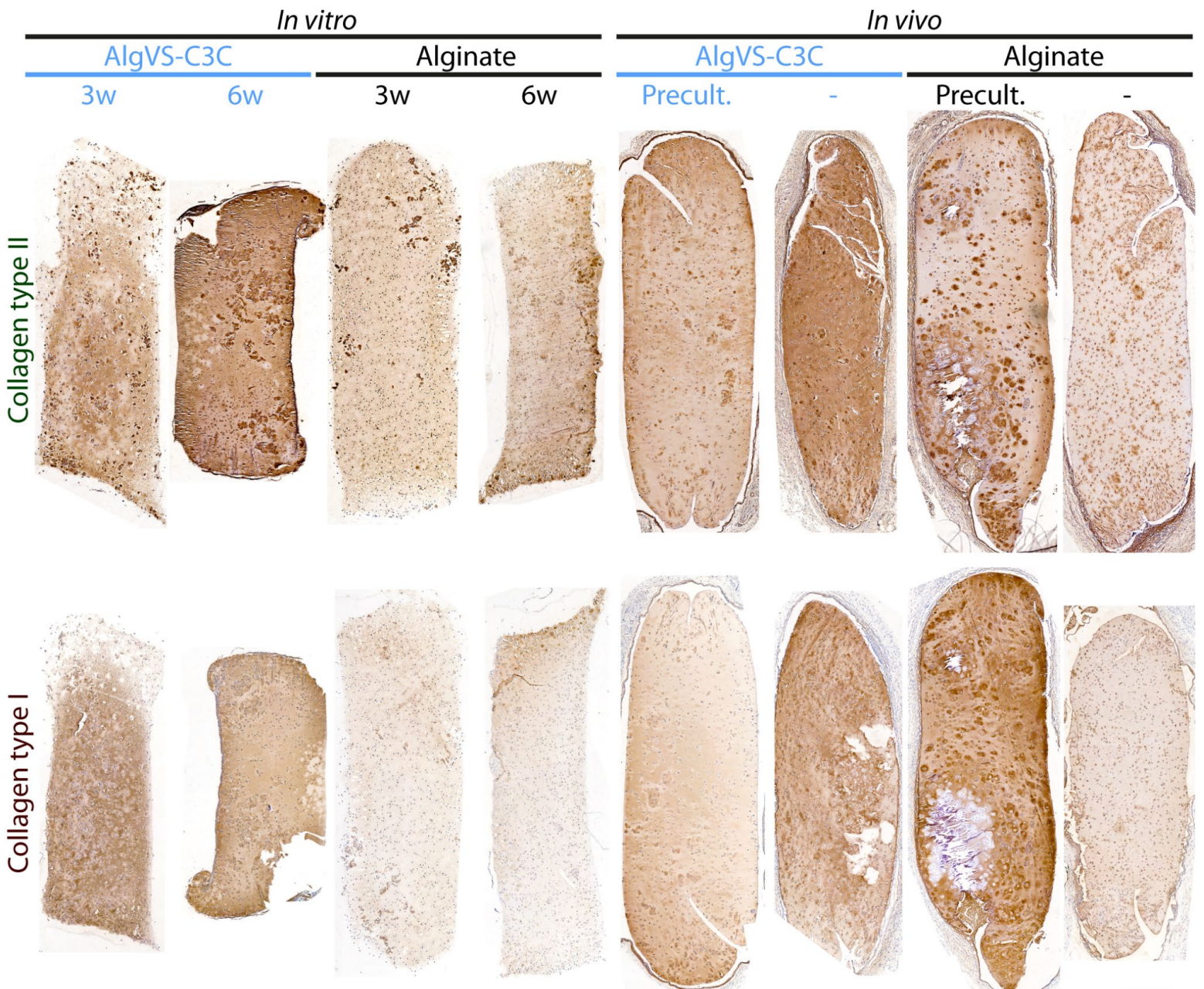

Cartilage explant (pos. control)
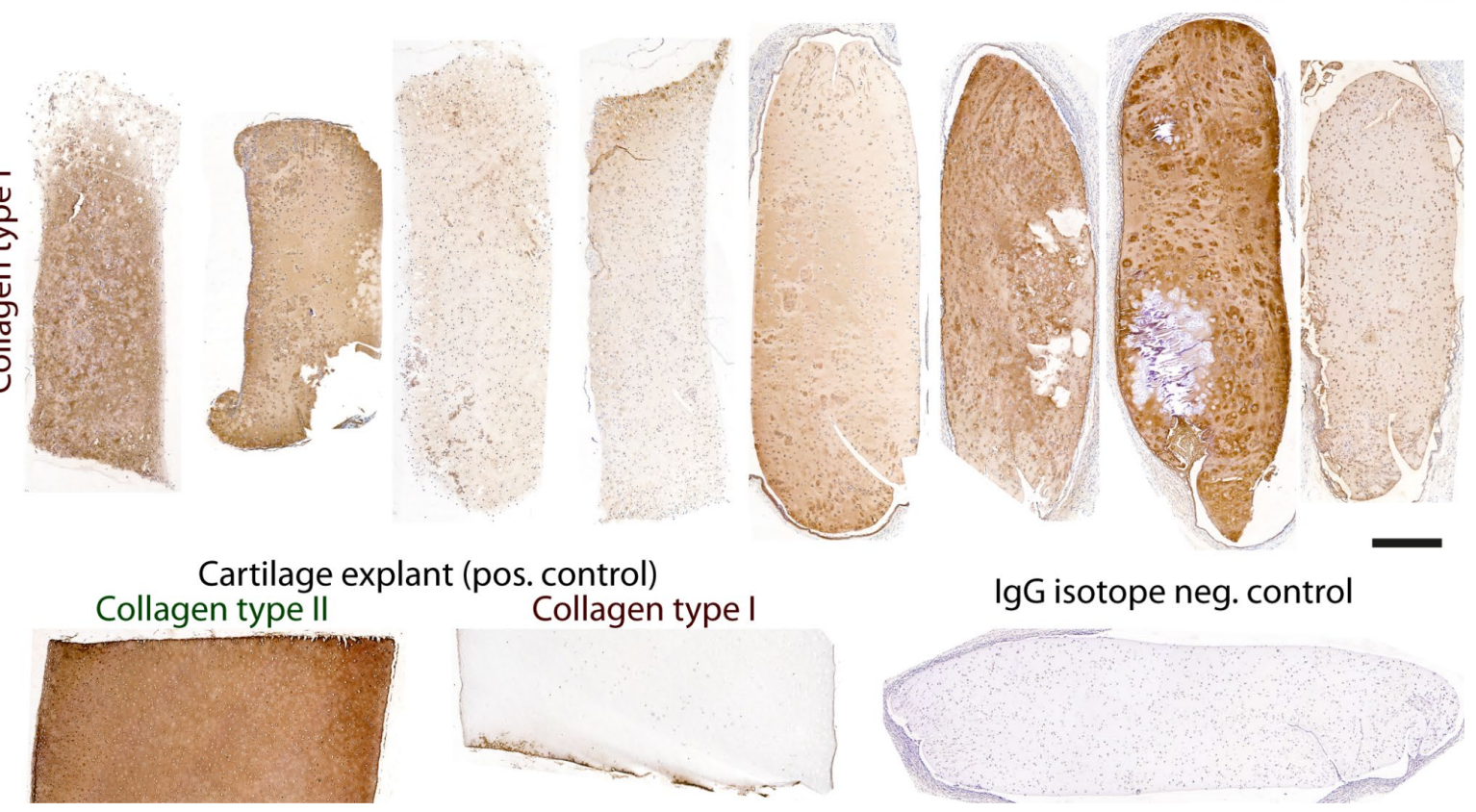

IgG isotope neg. control

Figure 8. (two-column, $17.5 \mathrm{~cm}$ ) Immunohistochemistry of AlgVS-C3C hydrogels in vitro and in vivo. AlgVS-C3C hydrogels (blue) were compared to alginate (black) in both in vitro (left) and in vivo (right) conditions. Immunohistochemistry was performed for collagen type II (upper row) and type I (middle row). Positive and negative controls are depicted on the lower row. The in vitro samples were cultured for three $(3 w)$ or six $(6 w)$ weeks while the in vivo samples were subcutaneously in the back of nude mice for three weeks, with (Precult.) or without (-) a three weeks preculture period. The samples without preculture led to the richest collagen type II matrix production in vivo; $n=3$ (in vitro), $n=4$ (in vivo). Scale bar: $500 \mu m$.

\section{Discussion}

Dysregulation of RhoA is implicated in a number of diseases including osteoarthritis, asthma, cancer, tumor metastasis, erectile dysfunction, glaucoma, neuronal degeneration and cardiovascular diseases. ${ }^{34}$ In 2016, more than 170 small-molecule ROCK inhibitors, a direct effector of RhoA, were reported. ${ }^{34}$ However, despite the significant interest and the many potential applications, relatively few inhibitors have reached the stage of clinical trials or received market authorization. The use of ROCK inhibitors in systemic therapies is strongly hindered by multiple side effects such as hypotension or vasodilatation. ${ }^{35}$ Nevertheless, two drugs have already been approved for clinical use. Fasudil, in 
Japan, is used to treat cerebral vasospasm and pulmonary hypertension and Ripasudil, in China, is used in the treatment of glaucoma and ocular hypertension. Related to the present work, a cell-permeable version of C3 transferase was developed (BA-210, VX-210, Cethrin) and clinical trials were started for acute spinal cord injury in phase $1 / 2 \mathrm{a}(\operatorname{Nov} 2013)^{36,37}$ and phase $2 \mathrm{~b} / 3$ (May 2018)..$^{38}$

In addition to the drug-specific side effects induced by systemic delivery, low bioavailability and short plasma half-lives are additional obstacles to an effective treatment, which can be overcome by local delivery strategies. Intra-articular injection, for example, effectively increases bioavailability while reducing off-target effects, although the drug is relatively quickly cleared from the joint. ${ }^{28}$ There is a need for systems that allow sustained retention of the therapeutics. Covalent immobilization of a drug onto an implanted scaffold could fulfill the requirements of prolonged residency time and local exposure..$^{39,40}$

The RhoA inhibitor used in the present work is a variant of the bacterial enzyme, C3 transferase. The activation of RhoA occurs via a guanine nucleotide exchange factor (GEF), which stimulates the exchange of guanosine diphosphate (GDP) by guanosine triphosphate (GTP). Thus, Rho GTPases act as a molecular switch, cycling between an active GTP-bound form and inactive GDP-bound form. ${ }^{41} \mathrm{C} 3$ transferase specifically ADP-ribosylates the active region of RhoA, RhoB and RhoC, thus permanently inactivating the GTPase. ${ }^{31}$ Since this is an intracellular process, it is important that the enzyme be both released from the matrix and uptaken by the cells. To achieve release, the protein was attached to the hydrogel via an MMP-cleavable linker, known to be expressed by osteoarthritic chondrocytes. ${ }^{30,42}$ Since RhoA is implicated in a number of cellular processes, its inhibition raised concerns about reduced cell viability. Chondrocytes treated with free $\mathrm{C} 3$ at $0.6 \mu \mathrm{g} / \mathrm{ml}$ for one week were viable and showed enhanced glycosaminoglycan production. ${ }^{20}$ It is believed that low concentrations of C3 transferase slow cell proliferation rather than reduce cell viability. ${ }^{20,43}$ More precisely, chondrocytes have an intrinsically low cell proliferation rate and it is known that they lose their chondrogenic phenotype upon passaging. To confirm that the engineered variant, C3C, did not impair chondrocyte viability, the free enzyme was incubated at different concentrations and the viability measured after one week. $A$ cytotoxic effect was only observed at concentrations above $3.2 \mu \mathrm{g} / \mathrm{ml}$.

The native form of C3 transferase has a low cell penetration rate, which strongly limits its efficacy. A commercial variant exists with enhanced cell permeation (e.g., СT04, Cytoskeleton, Denver, CO, USA). In this commercial product, a proprietary sequence was conjugated to C3 transferase via a disulfide bridge and showed high efficacy in vitro. The manufacturer recommends concentrations up to 2.0 $\mu \mathrm{g} / \mathrm{ml}$. Although there is no strong consensus on the best cell-penetrating peptide, the most widely used approach is the sequence from the HIV-1 Tat protein added to the N-terminus of the fusion protein. ${ }^{44}$ Due to the addition of protein fragments at both ends of the $\mathrm{C} 3$ transferase, concerns about reduced enzymatic activity were raised. A protocol was previously published to measure the glycohydrolase activity of $\mathrm{C} 3$ exoenzyme using a fluorescent analog of $\mathrm{NAD}^{+} .{ }^{31}$ This assay was based on the 10 -fold fluorescence increase between the substrate, $\varepsilon-N A D^{+}$, and the product, $\varepsilon$-ADP-ribose. By monitoring the fluorescence of the reaction mixture $\left(\lambda_{\mathrm{ex}} 305 \mathrm{~nm} ; \lambda_{\mathrm{em}} 410 \mathrm{~nm}\right)$, the glycohydrolase activity of the enzyme was measured. However, this procedure is incompatible with proteins purified by histidine affinity chromatography, without post-purification. Indeed, this purification method requires high concentrations of imidazole, which has a fluorescence profile similar to $\varepsilon$-ADP-ribose, thus interfering with the fluorescence measurement. To overcome this limitation, an HPLC-based method by A. Gasser and A. H. Guse ${ }^{45}$ was adapted to allow the simultaneous measurement of the substrate $\left(\mathrm{NAD}^{+}\right)$, the product (ADP-ribose) and the degradation product (AMP) concentrations, by measuring the absorbance at $270 \mathrm{~nm}$, and avoiding imidazole interference. 
Polysaccharide modifications reported in the scientific literature sometimes cause a substantial molecular weight loss, due to the harsh environment used for the functionalization, which in turn affects the mechanical strength of the hydrogel. For this reason, it was crucial that the two-step reaction leading to alginate vinyl sulfone did not degrade the polymer. This procedure was developed to allow good control of the degree of functionalization, in mild conditions, which prevented polymer degradation. ${ }^{46}$ Functionalizing polymers with vinyl sulfone moieties was performed on several polymers with no detrimental effect on chondrocyte viability; specifically, PEG-VS was synthesized and further functionalized with peptides ${ }^{47}$; galactaric acid-lysine copolymer functionalized with vinyl sulfone was used in cartilage engineering ${ }^{48}$ and hyaluronan-VS was used as an intermediate for the synthesis of hyaluronan-transglutaminase. ${ }^{46}$ However, free vinyl sulfone exhibits high cytotoxicity. To remove unconjugated vinyl sulfone molecules, AlgVS was extensively dialyzed after synthesis. Furthermore, AlgVS was incubated with free cysteine after Michael addition to C3C to quench unreacted vinyl sulfone moieties.

When chondrocytes were encapsulated in the C3C-loaded gels, the scaffolds became, over time, progressively more opaque, suggesting the production of extracellular matrix. Another observation suggesting a higher metabolic activity and matrix production was the faster media color change, compared to the unloaded hydrogels. Generally, chondrogenesis (e.g., induced by TGF- $\beta$ ) and the consequent increased in matrix production are accompanied by faster acidification of the culture media. In most chondrogenic materials, a strong link between collagen type II (characteristic of hyaline cartilage) and type I (characteristic of fibrocartilage) is observed. An upregulation of collagen type II often leads to simultaneous upregulation of type I, which was also observed in our construct, AlgVSC3C. After a six-week culture time, the intensity of the collage type II immunostaining was similar to that of native cartilage. A substantial difference can be observed between week 3 and week 6 , confirming a continuous matrix deposition and a sustained enzymatic activity. Covalently bound C3C was active for extended periods of time, while it is unlikely that a single dose of any unconjugated therapeutic molecule remains active in the site of action for several weeks. Chondrogenic differentiation of MSCs is generally believed to take around three weeks, ${ }^{49}$ although other studies aiming at developing osteochondral grafts focused on a six-week timeframe. ${ }^{50}$ The timescale of chondrogenesis is still undergoing investigation and was shown to vary according to the microenvironment of the cell. ${ }^{50}$

Overall, when implanting the AlgVS-C3C hydrogels in the back of nude mice, AlgVS-C3C samples produced more collagen type II than the alginate controls. However, some differences were observed between samples that were precultured and freshly prepared hydrogels. Even with a three-week preculture time allowing the chondrocytes to produce a collagen type II-rich extracellular matrix in vitro, the intensity of immunohistochemical staining after harvesting the samples from the mice was higher in freshly prepared samples. Therefore, freshly prepared AlgVS-C3C samples are believed to be the best option for cartilaginous matrix production in a subcutaneous implantation model. It should be noted that chondrogenesis is not fully characterized by the sole amount of collagen types I and II. The SOX transcription factors, non-collagenous proteoglycans (e.g., aggrecan) or hypertrophic markers play an important role in the quality of the engineered construct. ${ }^{49}$ Consequently, more work is needed to understand the interplay between the different markers in order to address all aspects of chondrogenesis.

\section{Conclusions}

In conclusion, a cell-instructive material inhibiting RhoA signaling was developed and tested for its ability to enhance chondrogenesis. It is known that chondrocytes respond to their three-dimensional environment to produce functional extracellular matrix. For example, chondrocytes quickly dedifferentiate when cultured on a two-dimensional substrate. The cells also strongly react to 
biochemical stimuli (i.e., such as TGF- $\beta$ or C3 transferase), that can help to avoid dedifferentiation and induce chondrogenesis. Combining mechanical and biochemical cues could represent a novel way of inducing the production of cartilaginous extracellular matrix. The cytoskeleton is known to play a central role in chondrogenic differentiation, which was enhanced by specific inhibition of RhoA. In this study, we developed a modified version of alginate, AlgVS, to allow its cross-linking to thiol-containing molecules. A variant of the bacterial inhibitor C3 transferase was designed, expressed and conjugated to AlgVS under physiological conditions. This chondrocyte-seeded material was assessed in vitro and in vivo and showed good biocompatibility, sustained enzymatic activity, and improved mechanical and chondrogenic properties. Due to the relevance of RhoA in many other tissues and cell types, we believe that the applicability of this construct extends beyond cartilage engineering and could play a role in treating other pathologies. 


\section{Materials and methods}

Chemicals. Unless otherwise stated, solvents and reagents were purchased from Sigma-Aldrich, Buchs, Switzerland.

Plasmid design. The C3 transferase sequence corresponds to nucleotides 1-654 of EMBL-EBI accession number X51464 from Clostridium botulinum (Uniprot P15879). On the N-terminus, a cell-penetrating peptide extracted from residues $48-60$ of the Tat protein (Human immunodeficiency virus, Uniprot P04608) was introduced and on the C-terminus, an MMP-cleavable sequence (GPQGIWGQ) and a cysteine cassette (ERCG) were added. Small linkers were added to space out the protein fragments. The protein tags were converted into DNA sequences using codons optimized for expression in $E$. coli and was flanked with Ndel and Xhol restriction sites to allow subcloning into the pET-26b expression vector (Novagen), expressing a polyhistidine-tag at the C-terminus. The plasmid map can be found in the supporting information. The synthesis as well the subcloning was performed externally (Biomatik, Wilmington, DE, USA) and $4 \mu \mathrm{g}$ of plasmid supplied as a lyophilized powder. Electrocompetent BL21 (DE3) E. coli cells were transformed by electroporation with $400 \mathrm{ng}$ of this plasmid, using standard protocols.

Protein expression and purification. A single colony was inoculated into $5 \mathrm{~mL}$ lysogeny broth (LB) + 50 $\mu \mathrm{g} / \mathrm{mL}$ kanamycin and grown overnight at $37^{\circ} \mathrm{C}$. The following morning, the preculture was diluted 1:100 into fresh $\mathrm{LB}+50 \mu \mathrm{g} / \mathrm{mL}$ kanamycin. The culture was grown at $37^{\circ} \mathrm{C}$ with $200 \mathrm{rpm}$ shaking until an $\mathrm{OD}_{600}$ of 0.4-0.6 was reached (about 2.5 hours). At this point, the cells were induced with $0.2 \mathrm{mM}$ isopropyl- $\beta$-D-thiogalactoside (IPTG), and the temperature lowered to $27^{\circ} \mathrm{C}, 180 \mathrm{rpm}$. The protein production was allowed to proceed for 20 hours, before pelleting the cells by centrifugation $(5000 \mathrm{~g}$, $15 \mathrm{~min}$ ). The supernatant was discarded and the pellet frozen. The pellet was thawed and resuspended in cold lysis buffer $\left(50 \mathrm{mM} \mathrm{NaH} \mathrm{PO}_{4}, 300 \mathrm{mM} \mathrm{NaCl}, 10 \mathrm{mM}\right.$ imidazole, $1 X$ protease inhibitor (cOmplete ${ }^{\mathrm{TM}}$ protease inhibitor cocktail, Roche, Basel, Switzerland), $1 \mathrm{mg} / \mathrm{mL}$ lysozyme, $\mathrm{pH}$ 8.0) (1 $\mathrm{mL} / 100 \mathrm{~mL}$ culture). The slurry was incubated $30 \mathrm{~min}$ on ice and sonicated using three 10 sec bursts at $50 \%$ intensity (Digital sonifier 250, Branson, Danbury CT, USA). The cell debris were separated by centrifugation $(16,000 \mathrm{~g}, 15 \mathrm{~min})$ and filtrated at $0.45 \mu \mathrm{m}$.

The $\mathrm{C} 3$ transferase (C3C) was purified by affinity purification on an automated chromatographic purifier (Äkta FPLC, GE Healthcare, Glattbrugg, Switzerland) under the following conditions. The Niaffinity chromatography was performed using a $1 \mathrm{~mL}$ HisTrap ${ }^{\mathrm{TM}} \mathrm{HP}$ column (GE Healthcare, Glattbrugg, Switzerland) with a two-step gradient of imidazole ( $20 \rightarrow 90 \mathrm{mM}$ in $3 \mathrm{CV}, 90 \rightarrow 250 \mathrm{mM}$ in $17 \mathrm{CV}$ ), 1 $\mathrm{mL} / \mathrm{min}$. The signal was recorded at $254 / 280 \mathrm{~nm}$, and fractions with an absorbance $>200 \mathrm{mAU}$ were collected and analyzed by polyacrylamide gel electrophoresis. Finally, the fractions containing the purified protein were pooled, aliquoted and frozen with $10 \%$ glycerol as cryoprotectant. The yield using this method was $\approx 4 \mathrm{mg} \mathrm{C3C}$ per liter of bacterial culture.

Alginate functionalization. Alginate (Pronova UP LVG, Novamatrix, Sandvika, Norway) was functionalized with vinyl sulfone moieties, with a target of $5 \%$ substitution. To $40 \mathrm{~mL}$ of a $150 \mathrm{mM}$ solution of 2-( $\mathrm{N}$-morpholino)ethanesulfonic acid (MES) in water were added $100 \mathrm{mg}$ alginate $(\approx 0.5$ $\mathrm{mmol}$ of the $-\mathrm{COOH}$ functional groups) and $3.0 \mathrm{mg} 3,3$ '-dithiobis(propanoic dihydrazide) (DTPHY; $0.0125 \mathrm{mmol}, 0.025 \mathrm{eq} / \mathrm{COOH}$; Frontier Scientific, Logan UT, USA) were added. The $\mathrm{pH}$ of the resulting mixture was 4.3. $4.8 \mathrm{mg}$ of $\mathrm{N}$-(3-Dimethylaminopropyl)- $\mathrm{N}^{\prime}$-ethylcarbodiimide (EDC; $0.025 \mathrm{mmol}, 0.05$ eq/ $\mathrm{COOH}$ ) were then dissolved in a small volume of $\mathrm{H}_{2} \mathrm{O}$, before adding to the alginate solution under vigorous stirring. The reaction was allowed to proceed overnight standing at room temperature. To reduce the disulfide bridges introduced by DTPHY, $11.5 \mathrm{mg}$ of tris(2-carboxyethyl)phosphine $\cdot \mathrm{HCl}$ (TCEP; $0.05 \mathrm{mmol}, 4$ eq/DTPHY); Fluorochem, Hadfield, United Kingdom), first dissolved in a small volume of $\mathrm{H}_{2} \mathrm{O}$, was added to the alginate solution and allowed to react overnight at RT with gentle 
shaking. The solution was then supplemented with $1 \mathrm{~g} \mathrm{NaCl}$ and dialyzed against acidified milliQ water (pH 5.0, $\left.10^{-5} \mathrm{M} \mathrm{HCl}\right)$.

Triethanolamine buffer ( $10 \mathrm{~mL}$ of $300 \mathrm{mM}$ solution, $\mathrm{pH}$ 8.0) was added to the recovered solution of thiolated alginate. Two hundred fifty $\mu \mathrm{L}$ divinyl sulfone $(2.5 \mathrm{mmol}, 200 \mathrm{eq} / \mathrm{DTPHY})$ was added and allowed to react for 3 hours at RT. Finally, $4 \mathrm{~g}$ of $\mathrm{NaCl}$ were added to the solution and dialyzed against milliQ water. The resulting alginate vinyl sulfone (AlgVS) was sterile-filtered before being aliquoted and lyophilized. The degree of substitution was calculated by ${ }^{1} \mathrm{H}$ NMR and was found to reach $5.3 \%$.

Gel permeation chromatography. The functionalized alginate was analyzed by gel permeation chromatography (GPC) using the following parameters: Column: Agilent AdvanceBio SEC $300 \AA$ $7.8 \times 300 \mathrm{~mm}, 2.7 \mu \mathrm{m}$; eluent: $\mathrm{Na}_{2} \mathrm{HPO}_{4} 60 \mathrm{mM}+\mathrm{NaH}_{2} \mathrm{PO}_{4} 40 \mathrm{mM}, \mathrm{pH} 7.0$; temperature: $30^{\circ} \mathrm{C}$; flow rate: $0.7 \mathrm{~mL} / \mathrm{min}$; runtime: $15 \mathrm{~min}$; detectors: absorbance at $214 \mathrm{~nm}$, refractive index.

Glycohydrolase activity measurement. C3 has, besides its ADP-ribosyltransferase activity a high glycohydrolase activity and can convert $\beta$-nicotinamide adenine dinucleotide $\left(N A D^{+}\right)$into adenosine diphosphate-ribose (ADPR) and nicotinamide. ${ }^{31}$

Ten $\mu \mathrm{L}$ of the purified C3C solution and $10 \mu \mathrm{L}$ of a $4 \mathrm{mM} \mathrm{NAD}^{+}$stock solution were diluted into $80 \mu \mathrm{L}$ reaction buffer ( $5 \mathrm{mM} \mathrm{MgCl}, 100 \mathrm{mM} \mathrm{KCl}, 20 \mathrm{mM}$ Tris, $\mathrm{pH}$ 7.5). The final protein and substrate concentrations were $0.5 \mu \mathrm{M}$ and $0.4 \mathrm{mM}$, respectively. The reaction mixture was gently mixed and left to react at $37^{\circ} \mathrm{C}$ up to 100 hours. At logarithmically-spaced time points, the reaction mixture was injected on HPLC under the following conditions. Column: ACE Equivalence C18, 4.6×250 mm, $5 \mu \mathrm{m}$ (Advanced Chromatography Technologies, Aberdeen, United Kingdom) kept at $30^{\circ} \mathrm{C}$; solvent system:

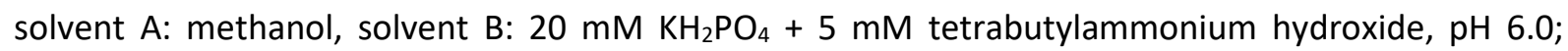
gradient in \% methanol (\% A): 0 min: 15\%, $3.5 \mathrm{~min}: 15 \%, 5.5 \mathrm{~min}: 32.5 \%, 6.5 \mathrm{~min}: 32.5 \%, 9 \mathrm{~min}: 40 \%$, $11 \mathrm{~min}$ : 50\%, $16 \mathrm{~min}:$ 50\%, $18 \mathrm{~min}:$ 15, $27 \mathrm{~min}$ : 15\%; detector: 214, $270 \mathrm{~nm}$; retention times: $8.0 \mathrm{~min}$ $\left(\mathrm{NAD}^{+}\right), 10.8 \mathrm{~min}(\mathrm{AMP}), 12.4 \mathrm{~min}(\mathrm{ADPR})$; run time: $27 \mathrm{~min}^{45}$

Fluorescent protein binding. Fluorescently-labeled bovine serum albumin (BSA) was used to assess protein binding to AlgVS. A solution of BSA-Texas Red (A23017, Thermo Fisher Scientific, Waltham MA, USA) at $0.25 \mathrm{mg} / \mathrm{mL}$ in $200 \mathrm{mM}$ borate buffer, $\mathrm{pH} 8.0$ was prepared. There are no details on the TexasRed conjugation on the manufacturer's website. Lyophilized AlgVS was dissolved in $150 \mathrm{mM} \mathrm{NaCl}$ at $2 \% \mathrm{w} / \mathrm{v}$ and mixed 1:1 with BSA-Texas Red. $40 \mu \mathrm{L}$ were pipetted onto a gel caster, which was immediately closed and immersed in $100 \mathrm{mM} \mathrm{CaCl}, 10 \mathrm{mM}$ HEPES, pH 7.4 for $30 \mathrm{~min}$. Following gelation, the samples were imaged on an epifluorescence microscope (Axio Observer.Z1, Zeiss, Oberkochen, Germany) and the integrated density was measured with ImageJ 1.51. The samples were then transferred to a large volume of $50 \mathrm{mM}$ HEPES, $150 \mathrm{mM} \mathrm{NaCl}, \mathrm{pH} 7.4$ and kept for seven days to elute unbound protein. After this incubation time, the amount of BSA-Texas Red retained in the hydrogels was quantified in the same way and normalized to the protein initially adsorbed. To account for fluorophore quenching, the fluorescence intensity of BSA-Texas Red was measured after seven days at RT using a conventional plate reader (data not shown).

Cell culture. The media used throughout the cell isolation and expansion was Dulbecco's Modified Eagle Medium (DMEM) (31966, Gibco, Thermo Fisher Scientific, Waltham MA, USA) supplemented with 10\% FBS (10270, Gibco, Thermo Fisher Scientific, Waltham MA, USA), $82 \mu \mathrm{g} / \mathrm{mL}$ L-ascorbic acid 2phosphate sesquimagnesium and $10 \mu \mathrm{g} / \mathrm{mL}$ gentamycin (15710, Gibco, Thermo Fisher Scientific, Waltham MA, USA). This media is referred to as "expansion media" in the following section. Bovine chondrocytes (bCh) were isolated from 6 months old calf knees, obtained from a local butcher. The cartilage pieces were first washed with PBS containing $50 \mu \mathrm{g} / \mathrm{mL}$ gentamycin and cut into smaller pieces $\left(1-2 \mathrm{~mm}^{3}\right)$. The minced cartilage was then enzymatically digested with collagenase $(0.12 \% \mathrm{w} / \mathrm{v}$, 
C6885) in expansion media for $5-6 \mathrm{~h}$ at $37^{\circ} \mathrm{C}$. The chondrocyte suspension thus obtained was filtrated with $100 \mu \mathrm{m}$ and $40 \mu \mathrm{m}$ cell strainers to remove undissolved cartilage pieces. The cells were pelleted, resuspended in recovery medium (12648, Gibco, Thermo Fisher Scientific, Waltham MA, USA) at $1.0 \times$ $10^{6}$ cells $/ \mathrm{mL}$ and frozen at passage 0 until further use.

For the cell viability measurements, human chondrocytes (hCh) were isolated using a similar procedure, under ethics approval \# KEK-ZH 2013-0097. The donors were aged between 21 and 38 years old cells were frozen at passage $1(\mathrm{P} 1)$.

Cell viability. The viability was measured on bovine and human chondrocytes at passage 1 , cultured in $2 \mathrm{D}$ at a seeding density of 2,000 cells $/ \mathrm{cm}^{2}$. The free C3C was added to the culture media in a concentration range $0.1-3.2 \mu \mathrm{g} / \mathrm{mL}$ and the cells kept for seven days before being quantified with 2 $\mu \mathrm{M}$ calcein $\mathrm{AM}$ and $1 \mu \mathrm{M}$ propidium iodide. The viability of bovine/human chondrocytes encapsulated at a cell concentration of $5 \times 10^{6}$ cells $/ \mathrm{mL}$ in AlgVS was measured after one week using the same assay and compared to cells encapsulated in alginate hydrogels. The imaging was performed with an epifluorescence microscope and images quantified with ImageJ 1.51.

Preparation of cell-seeded protein-loaded hydrogels. P1 bCh were suspended in expansion media at $15-20 \times 10^{6}$ cells $/ \mathrm{mL}$. In parallel and one day before cell encapsulation, AlgVS was dissolved in $100 \mathrm{mM}$ HEPES, $\mathrm{pH} 8.0$ at $2 \% \mathrm{w} / \mathrm{v}$. C3C was added to this hydrogel precursor solution at a concentration of 32 $\mu \mathrm{g} / \mathrm{mL}$ (measured by SDS-PAGE). The Michael Addition was allowed to proceed for 24 hours at $30^{\circ} \mathrm{C}$, with shaking, and the unreacted vinyl sulfone moieties were quenched by the addition of $100 \mathrm{mM}$ cysteine for 8 hours. The cells were mixed 1:1 with the gel component and $40 \mu \mathrm{L}$ were deposited on the gel casters, as described previously. Consequently, each hydrogel contains $1 \%$ AlgVS, $0.4 \mu \mathrm{g} \mathrm{C3C}$ and $3-4 \times 10^{5}$ cells. The caster was closed and immersed in pre-warmed, sterile $100 \mathrm{mM} \mathrm{CaCl}, 10 \mathrm{mM}$ HEPES, pH 7.4 for $30 \mathrm{~min}$. The gels were transferred to expansion media, and the media was changed twice a week.

Gene expression. To assess the effect of $\mathrm{C} 3 \mathrm{C}$ on extracellular matrix biosynthesis, bovine chondrocytes were encapsulated in $1 \% \mathrm{w} / \mathrm{v}$ unmodified alginate and exposed to $0.4 \mu \mathrm{g} / \mathrm{mL}$ free $\mathrm{C} 3 \mathrm{C}$ (added to the culture media) or encapsulated in $1 \% \mathrm{w} / \mathrm{v}$ AlgVS-C3C. An untreated control condition was performed where cells were encapsulated in $1 \% \mathrm{w} / \mathrm{v}$ unmodified alginate, without $\mathrm{C} 3 \mathrm{C}$ supplementation. After three weeks of culture, the gels were snap-frozen in liquid $\mathrm{N}_{2}$ and the RNA extracted using a NucleoSpin RNA kit (Macherey-Nagel, Düren, Germany) according to manufacturer's instructions. RNA was transcribed to cDNA using SuperScript III (Thermo Fisher Scientific, Waltham MA, USA) and amplified by quantitative real-time PCR (StepOnePlus, Applied Biosystems, Thermo Fisher Scientific, Waltham MA, USA) with SYBR ${ }^{\circledR}$ Green master mix. The genes analyzed were RPL13a (internal reference gene; FWD 5'-GCCAAGATCCACTATCGGAAA-3', REV 5'-AGGACCTCTGTGAATTTGCC-3'), collagen type I (COL1A2; FWD 5'-CGAGGGCAACAGCAGATTCACTTA-3, REV 5'-GCAGGCGAGATGGCTTGTTTG-3'), collagen type II (COL2A1; FWD 5'-GGCCAGCGTCCCCAAGAA-3', REV 5'-AGCAGGCGCAGGAAGGTCAT- 3') and transcription factor SOX9 (SOX9; FWD 5'-ACGCGGCCCCAGGAGAAC-3', REV 5'CGGATGCACACGGGGAACTT-3').

Mechanical testing. The mechanical properties of the scaffolds were measured under unconfined compression, using a TA.XTplus Texture Analyser (Stable Micro Systems, Godalming, United Kingdom) with a $500 \mathrm{~g}$ load cell and a $\varnothing 15 \mathrm{~mm}$ probe. To prepare the gels, unmodified alginate or AlgVS was dissolved at $1 \% \mathrm{w} / \mathrm{v}$ in $150 \mathrm{mM} \mathrm{NaCl}$. After complete dissolution, $40 \mu \mathrm{L}$ was pipetted onto gel casters and immersed in $100 \mathrm{mM} \mathrm{CaCl}_{2}$ for 30 minutes. The gel dimensions using this procedure were $\varnothing 6 \times 1.5$ $\mathrm{mm}$. Directly after, the gels were transferred onto the measuring plate and compressed at a speed of $0.02 \mathrm{~mm} / \mathrm{sec}$. The sampling rate was set at 10 measurements/data point, and each condition was 
performed in triplicate. The compressive modulus $E$ was calculated between $5 \%$ and $15 \%$ strain, according to the following formula:

$$
E=\frac{F / A_{0}}{\Delta L / L_{0}}[k P a]
$$

where $F$ is the applied load $[\mathrm{mN}], A_{0}$ the initial surface area $\left[\mathrm{mm}^{2}\right], L_{0}$ the initial height $[\mathrm{mm}]$ and $\Delta L$ is the height difference [mm]. The shear modulus $\mu$ was calculated by fitting the data to $90 \%$ strain using the below formula:

$$
\sigma=-2 \frac{\mu}{\alpha} *\left(\left(1-\frac{\epsilon}{100}\right)^{\alpha-1}-\left(1-\frac{\epsilon}{100}\right)^{-\frac{\alpha}{2}-1}\right)[k P a]
$$

where $\sigma$ is the measured stress [kPa], $\varepsilon$ is the applied strain [\%], $\mu$ the shear modulus [kPa] and $\alpha$ a material constant [-].

Immunohistochemistry. The samples were fixed for $30 \mathrm{~min}$ in $4 \%$ formaldehyde, $150 \mathrm{mM} \mathrm{NaCl}, 10 \mathrm{mM}$ $\mathrm{CaCl}_{2}, 10 \mathrm{mM}$ HEPES, pH 7.4. $10 \mathrm{mM} \mathrm{CaCl}_{2}$ were added to all subsequent solutions to avoid hydrogel dissolution. The samples were then dehydrated by incubating the samples in ethanol/saline baths (20\%, 40\%,60\%, $45 \mathrm{~min} /$ bath). Subsequently, the dehydrated gels were embedded in paraffin with an automated embedder (Milestone Logos J, Sorisole, Italy). With a microtome (HM 325, Microm, Walldorf, Germany), $8 \mu \mathrm{m}$-thick longitudinal slices were cut. The sections were then deparaffinized with two xylene baths and a series of baths with decreasing ethanol content. Here again, $10 \mathrm{mM} \mathrm{CaCl}_{2}$ was added to the baths containing $<60 \%$ ethanol.

The buffer used for the immunohistochemical stainings was $150 \mathrm{mM} \mathrm{NaCl}, 10 \mathrm{mM} \mathrm{CaCl}, 10 \mathrm{mM} \mathrm{HEPES}$, $\mathrm{pH}$ 7.4. For collagen types I and II, the following polyclonal antibodies were used: ab138492 (Abcam, Cambridge, United Kingdom) and 600-401-104 (Rockland, Limerick PA, USA; RRID:AB_217572). The antigen retrieval was performed by first exposing the samples to $0.2 \%$ hyaluronidase for $30 \mathrm{~min}$ at 37 ${ }^{\circ} \mathrm{C}$. The sections were then blocked with $10 \%$ normal goat serum (50197Z, Gibco, Thermo Fisher Scientific, Waltham MA, USA) and incubated overnight with the primary antibodies at a 1:1500 and 1:200 dilution, for collagen types I and II, respectively. For colorimetric detection, endogenous peroxidase activity was blocked for $15 \mathrm{~min}$ with $0.3 \% \mathrm{H}_{2} \mathrm{O}_{2}$. After washing, the samples were exposed to Goat Anti-Rabbit IgG H\&L (HRP) at 1:1000 dilution (ab6721, Abcam, Cambridge, United Kingdom; RRID:AB_955447) for $1 \mathrm{~h}$ at RT. The samples were washed again and allowed to react with the DAB substrate (ab64238, Abcam, Cambridge, United Kingdom) for precisely 2 min. To stain nuclei, Mayer's hematoxylin (MHS1) was added for 3 min. The slides were washed, dehydrated with $95 \%$ and $100 \%$ ethanol and mounted. For fluorescent detection, the samples were incubated with anti-Rabbit IgG Secondary Antibody, Alexa Fluor 488/594 conjugate (A-11008/A-11037, Thermo Fisher Scientific, Waltham MA, USA; RRID:AB_143165/RRID:AB_2534095) for $1 \mathrm{~h}$ at RT. For nuclear staining, the slides were stained with DAPI for $15 \mathrm{~min}$. Finally, the sections were washed and mounted. The images were acquired on an automated slide scanner (Pannoramic 250 Flash II, 3Dhistech, Budapest, Hungary).

Subcutaneous implantation in nude mice. The protein-loaded hydrogels were made as previously described, using bCh P1 as a cell source. The final cell concentration was $8 \times 10^{6}$ cells $/ \mathrm{mL}$. The first set of samples were made right before the surgery while the second set of samples was made three weeks before surgery and kept in expansion medium. Samples were implanted in the back of a nude mice model $(n=4)$ according to Cantonal Guidelines for animal experimentation (License No. ZH118/2017). After three additional weeks, the mice were euthanized, and the scaffolds were analyzed by immunohistochemistry as described above. 
Statistical analysis. Quantitative data are expressed as mean \pm standard deviation. Ratio statistics was used to evaluate protein retention (Figure 4). One-way ANOVA with Dunnett multicomparison was used to compare cell viabilities (Figure 6). Two-way ANOVA with Dunnett multicomparison was conducted to compare genes expression (Figure 6). The mechanical properties (Figure 7) were evaluated with one-way ANOVA with Tukey multicomparison. One-/two-way analyses of variance were performed with GraphPad Prism 7 and ratio statistics with IBM SPSS Statistics 24. Differences were considered as significant for $p<0.05$, unless otherwise specified.

\section{Acknowledgments}

This work was funded by Swiss National Science Foundation (315230_159783) and FIFA/F-MARC (FIFA Medical Assessment and Research Center). The authors would like to sincerely thank Dr. Greta Faccio for feedback in fusion protein design, Nadine Lobsiger for preliminary works in optimizing protein expression and Dr. Mareike Bindszus and Prof. Manfred Kopf for access and assistance with the FPLC hardware. The authors acknowledge use of the Scientific Center for Optical and Electron Microscopy (ScopeM) of ETH Zürich.

\section{Author contributions}

F.A.F. and M.Z.-W. designed the research. F.A.F. conducted the experiments with the help of N.B. (hydrogel synthesis) and E.C. (in vivo experiments and immunohistochemistry). F.A.F. analyzed the data and wrote the manuscript and M.Z.-W. revised it.

\section{References}

(1) Hodge, R. G.; Ridley, A. J. Regulating Rho GTPases and Their Regulators. Nat. Rev. Mol. Cell Biol. 2016, $17(8), 496-510$.

(2) Discher, D. E.; Janmey, P.; Wang, Y. Tissue Cells Feel and Respond to the Stiffness of Their Substrate. Science (80-. ). 2005, 310 (NOVEMBER), 1139-1144.

(3) Tojkander, S.; Gateva, G.; Lappalainen, P. Actin Stress Fibers - Assembly, Dynamics and Biological Roles. J. Cell Sci. 2012, 125 (8), 1855-1864.

(4) Fletcher, D. A.; Mullins, R. D. Cell Mechanics and the Cytoskeleton. Nature 2010, 463 (January), 485-492.

(5) Kumar, D.; Lassar, A. B. The Transcriptional Activity of Sox9 in Chondrocytes Is Regulated by RhoA Signaling and Actin Polymerization. Mol. Cell. Biol. 2009, 29 (15), 4262-4273.

(6) Alberts, B.; Johnson, A.; Lewis, J. How Cells Regulate Their Cytoskeletal Filaments. In Molecular Biology of the Cell; Garland Sciences: New York, 2002.

(7) Arthur, W. T.; Burridge, K. RhoA Inactivation by P190RhoGAP Regulates Cell Spreading and Migration by Promoting Membrane Protrusion and Polarity. Mol. Biol. Cell 2001, 12 (9), 27112720.

(8) Wojnacki, J.; Quassollo, G.; Marzolo, M. P.; Cáceres, A. Rho GTPases at the Crossroad of Signaling Networks in Mammals: Impact of Rho-GTPases on Microtubule Organization and Dynamics. Small GTPases 2014, 5 (March).

(9) Mcbeath, R.; Pirone, D. M.; Nelson, C. M.; Bhadriraju, K.; Chen, C. S. Cell Shape, Cytoskeletal Tension, and RhoA Regulate Stem Cell Lineage Commitment. Dev. Cell 2004, 6, 483-495.

(10) Docheva, D.; Padula, D.; Popov, C.; Mutschler, W.; Clausen-Schaumann, H.; Schieker, M. Researching into the Cellular Shape, Volume and Elasticity of Mesenchymal Stem Cells, Osteoblasts and Osteosarcoma Cells by Atomic Force Microscopy: Stem Cells. J. Cell. Mol. Med. 2008, 12 (2), 537-552. 
600

601

602

603

604

605

606

607

608

609

610

611

612

613

614

615

616

617

618

619

620

621

622

623

624

625

626

627

628

629

630

631

632

633

634

635

636

637

638

639

640

641

(11) Haudenschild, D. R.; Chen, J.; Steklov, N.; Lotz, M. K.; D'Lima, D. D. Characterization of the Chondrocyte Actin Cytoskeleton in Living Three-Dimensional Culture: Response to Anabolic and Catabolic Stimuli. Mol. Cell. Biomech. 2009, 6 (3), 135-144.

(12) Rottmar, M.; Mhanna, R.; Guimond-Lischer, S.; Vogel, V.; Zenobi-Wong, M.; Maniura-Weber, K. Interference with the Contractile Machinery of the Fibroblastic Chondrocyte Cytoskeleton Induces Re-Expression of the Cartilage Phenotype through Involvement of PI3K, PKC and MAPKs. Exp. Cell Res. 2014, 320 (2), 175-187.

(13) Connelly, J. T.; García, A. J.; Levenston, M. E. Interactions between Integrin Ligand Density and Cytoskeletal Integrity Regulate BMSC Chondrogenesis. J. Cell. Physiol. 2008, 217 (1), 145-154.

(14) Woods, A.; Beier, F. RhoA/ROCK Signaling Regulates Chondrogenesis in a Context-Dependent Manner. J. Biol. Chem. 2006, 281 (19), 13134-13140.

(15) Woods, A.; Wang, G.; Beier, F. RhoA/ROCK Signaling Regulates Sox9 Expression and Actin Organization during Chondrogenesis. J. Biol. Chem. 2005, 280 (12), 11626-11634.

(16) Cai, S. A.; Fu, X.; Sheng, Z. Dedifferentiation : A New Approach in Stem Cell Research. Bioscience 2007, $57(8), 655-662$.

(17) Parreno, J.; Raju, S.; Niaki, M. N.; Andrejevic, K.; Jiang, A.; Delve, E.; Kandel, R. Expression of Type i Collagen and Tenascin C Is Regulated by Actin Polymerization through MRTF in Dedifferentiated Chondrocytes. FEBS Lett. 2014, 588 (20), 3677-3684.

(18) Parmacek, M. S. Myocardin-Related Transcription Factors: Critical Coactivators Regulating Cardiovascular Development and Adaptation. Circ. Res. 2007, 100 (5), 633-644.

(19) Wang, G.; Woods, A.; Sabari, S.; Pagnotta, L.; Stanton, L. A.; Beier, F. RhoA/ROCK Signaling Suppresses Hypertrophic Chondrocyte Differentiation. J. Biol. Chem. 2004, 279 (13), 1320513214.

(20) Öztürk, E.; Despot-Slade, E.; Pichler, M.; Zenobi-Wong, M. RhoA Activation and Nuclearization Marks Loss of Chondrocyte Phenotype in Crosstalk with Wnt Pathway. Exp. Cell Res. 2017, 360 (2), 113-124.

(21) Haudenschild, D. R.; Chen, J.; Pang, N.; Lotz, M. K.; D'Lima, D. D. Rho Kinase-Dependent Activation of SOX9 in Chondrocytes. Arthritis Rheum. 2010, 62 (1), 191-200.

(22) Appleton, C. T. G.; Usmani, S. E.; Mort, J. S.; Beier, F. Rho/ROCK and MEK/ERK Activation by Transforming Growth Factor- $\alpha$ Induces Articular Cartilage Degradation. Lab. Investig. 2010, 90 (1), 20-30.

(23) Pawar, S. N.; Edgar, K. J. Chemical Modification of Alginates in Organic Solvent Systems. Biomacromolecules 2011, 12, 4095-4103.

(24) Zhao, W.; Jin, X.; Cong, Y.; Liu, Y.; Fu, J. Degradable Natural Polymer Hydrogels for Articular Cartilage Tissue Engineering. J. Chem. Technol. Biotechnol. 2013, 88 (3), 327-339.

(25) Drury, J. L.; Mooney, D. J. Hydrogels for Tissue Engineering: Scaffold Design Variables and Applications. Biomaterials 2003, 24 (24), 4337-4351.

(26) Peppas, N. A.; Hilt, J. Z.; Khademhosseini, A.; Langer, R. Hydrogels in Biology and Medicine: From Molecular Principles to Bionanotechnology. Adv. Mater. 2006, 18 (11), 1345-1360.

(27) Natale, C. F.; Ventre, M.; Netti, P. A. Tuning the Material-Cytoskeleton Crosstalk via Nanoconfinement of Focal Adhesions. Biomaterials 2014, 35 (9), 2743-2751.

(28) Epstein-Barash, H.; Stefanescu, C. F.; Kohane, D. S. An in Situ Cross-Linking Hybrid Hydrogel for 
643

644

645

646

647

648

649

650

651

652

653

654

655

656

657

658

659

660

661

662

663

664

665

666

667

668

669

670

671

672

673

674

675

676

677

678

679

680

681

682

683

(29) Aktories, K.; Koch, G. Clostridium Botulinum ADP-Ribosyltransferase C3. Bact. toxins 2002, 1, 61-69.

(30) Akkiraju, H.; Nohe, A. Role of Chondrocytes in Cartilage Formation, Progression of Osteoarthritis and Cartilage Regeneration. J. Dev. Biol. 2015, 3 (4), 177-192.

(31) Lasko, D.; McKerracher, L. Fluorescent Assay of Cell-Permeable C3 Transferase Activity. Methods Enzymol. 2006, 406 (06), 512-520.

(32) Mihai, L. A.; Chin, L.; Janmey, P. A.; Goriely, A. A Comparison of Hyperelastic Constitutive Models Applicable to Brain and Fat Tissues. J. R. Soc. Interface 2015, 12 (110), 20150486.

(33) Ogden, R. W.; Saccomandi, G.; Sgura, I. Fitting Hyperelastic Models to Experimental Data. Comput. Mech. 2004, 34 (6), 484-502.

(34) Feng, Y.; Lograsso, P. V.; Defert, O.; Li, R. Rho Kinase (ROCK) Inhibitors and Their Therapeutic Potential. J. Med. Chem. 2016, 59 (6), 2269-2300.

(35) Chan, S. Y.; Loscalzo, J. Pulmonary Arterial Hypertension, Second Edi.; Elsevier Inc.: Philadelphia, PA, 2013.

(36) McKerracher, L.; Anderson, K. D. Analysis of Recruitment and Outcomes in the Phase I/Ila Cethrin Clinical Trial for Acute Spinal Cord Injury. J. Neurotrauma 2013, 30 (21), 1795-1804.

(37) Fehlings, M. G.; Theodore, N.; Harrop, J.; Maurais, G.; Kuntz, C.; Shaffrey, C. I.; Kwon, B. K.; Chapman, J.; Yee, A.; Tighe, A. A Phase I/lla Clinical Trial of a Recombinant Rho Protein Antagonist in Acute Spinal Cord Injury. J. Neurotrauma 2011, 28 (May), 787-796.

(38) Fehlings, M. G.; Kim, K. D.; Aarabi, B.; Rizzo, M.; Bond, L. M.; McKerracher, L.; Vaccaro, A. R.; Okonkwo, D. O. Rho Inhibitor VX-210 in Acute Traumatic Subaxial Cervical Spinal Cord Injury: Design of the SPinal Cord Injury Rho Inhibition InvestiGation (SPRING) Clinical Trial. J. Neurotrauma 2018, 35 (9), 1049-1056.

(39) Greenwald, R. B.; Yang, K.; Zhao, H.; Conover, C. D.; Lee, S.; Filpula, D. Controlled Release of Proteins from Their Poly(Ethylene Glycol) Conjugates: Drug Delivery Systems Employing 1,6Elimination. Bioconjug. Chem. 2003, 14 (2), 395-403.

(40) Li, J.; Mooney, D. J. Designing Hydrogels for Controlled Drug Delivery. Nat. Rev. Mater. 2016, 1 (12), 1-17.

(41) Dubash, A. D.; Guilluy, C.; Srougi, M. C.; Boulter, E.; Burridge, K.; García-Mata, R. The Small GTPase RhoA Localizes to the Nucleus and Is Activated by Net1 and DNA Damage Signals. PLoS One 2011, 6 (2).

(42) Van Hove, A. H.; G. Beltejar, M. J.; Benoit, D. S. W. Development and Invitro Assessment of Enzymatically-Responsive Poly(Ethylene Glycol) Hydrogels for the Delivery of Therapeutic Peptides. Biomaterials 2014, 35 (36), 9719-9730.

(43) von Elsner, L.; Hagemann, S.; Just, I.; Rohrbeck, A. C3 Exoenzyme Impairs Cell Proliferation and Apoptosis by Altering the Activity of Transcription Factors. Naunyn. Schmiedebergs. Arch. Pharmacol. 2016, 389 (9), 1021-1031.

(44) Reissmann, S. Cell Penetration: Scope and Limitations by the Application of Cell-Penetrating Peptides. J. Pept. Sci. 2014, 20 (10), 760-784.

(45) Gasser, A.; Guse, A. H. Determination of Intracellular Concentrations of the TRPM2 Agonist ADP-Ribose by Reversed-Phase HPLC. J. Chromatogr. B Anal. Technol. Biomed. Life Sci. 2005, 
821 (2), 181-187.

(46) Broguiere, N.; Isenmann, L.; Zenobi-Wong, M. Novel Enzymatically Cross-Linked Hyaluronan Hydrogels Support the Formation of 3D Neuronal Networks. Biomaterials 2016, 99, 47-55.

(47) Jin, R.; Teixeira, L. S. M.; Krouwels, A.; Dijkstra, P. J.; Van Blitterswijk, C. A.; Karperien, M.; Feijen, J. Synthesis and Characterization of Hyaluronic Acid-Poly(Ethylene Glycol) Hydrogels via Michael Addition: An Injectable Biomaterial for Cartilage Repair. Acta Biomater. 2010, 6 (6), 1968-1977.

(48) Chawla, K.; Yu, T. bin; Stutts, L.; Yen, M.; Guan, Z. Modulation of Chondrocyte Behavior through Tailoring Functional Synthetic Saccharide-Peptide Hydrogels. Biomaterials 2012, 33 (26), 60526060.

(49) Herlofsen, S. R.; Küchler, A. M.; Melvik, J. E.; Brinchmann, J. E. Chondrogenic Differentiation of Human Bone Marrow-Derived Mesenchymal Stem Cells in Self-Gelling Alginate Discs Reveals Novel Chondrogenic Signature Gene Clusters. Tissue Eng. Part A 2011, 17 (7-8), 1003-1013.

(50) Augst, A.; Marolt, D.; Freed, L. E.; Vepari, C.; Meinel, L.; Farley, M.; Fajardo, R.; Patel, N.; Gray, M.; Kaplan, D. L.; et al. Effects of Chondrogenic and Osteogenic Regulatory Factors on Composite Constructs Grown Using Human Mesenchymal Stem Cells, Silk Scaffolds and Bioreactors. J. R. Soc. Interface 2008, 5 (25), 929-939. 
702 TOC graphic

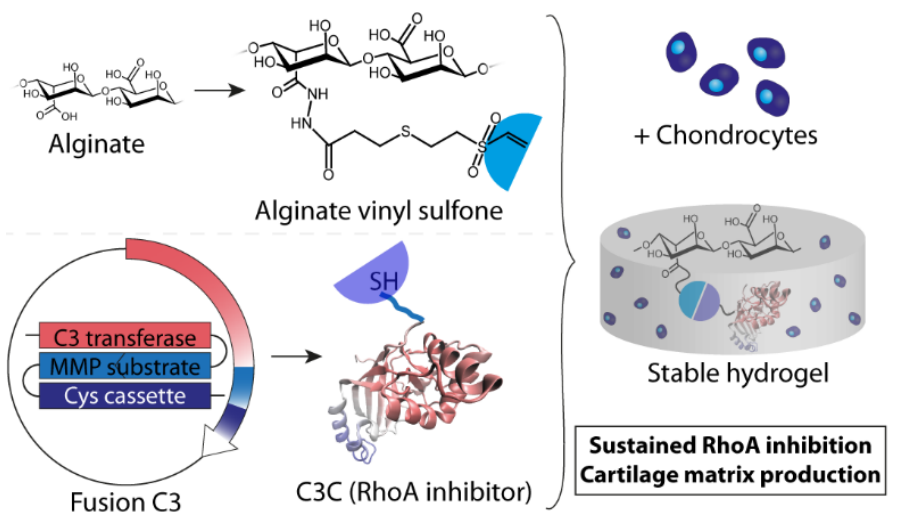

